\title{
Critical Issues for Parents with Mental Illness and their Families
}

\author{
Joanne Nicholson, Ph.D. \\ Kathleen Biebel, M.S. \\ Betsy Hinden, Ph.D. \\ Alexis Henry, Sc.D. \\ Lawrence Stier
}

Center for Mental Health Services Research
Department of Psychiatry
University of Massachusetts Medical School

Prepared for the Center for Mental Health Services

Substance Abuse and Mental Health Services Administration

Office of Policy, Planning and Administration

5600 Fishers Lane, Room 17C-02

Rockville, MD 20857

www.mentalhealth.org

$$
\text { 1-800-790-2647 }
$$

July 30, 2001 


\section{Table of Contents}

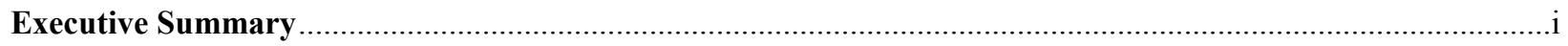

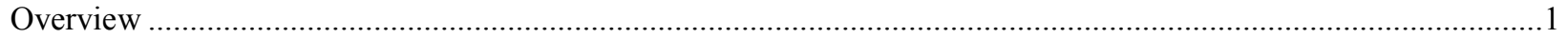

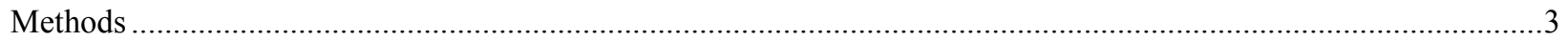

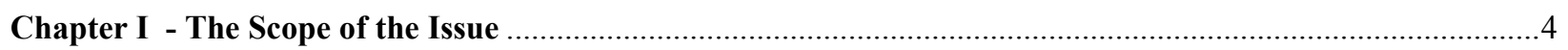

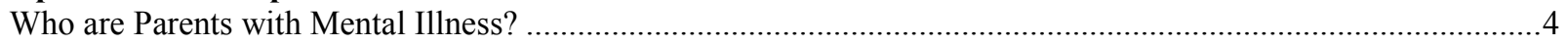

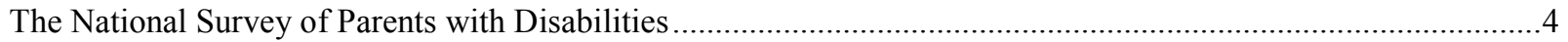

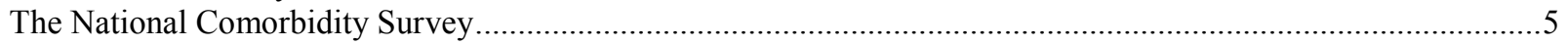

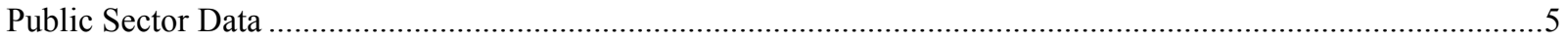

Chapter II - The Experiences of Parents with Mental IIlness..........................................................................

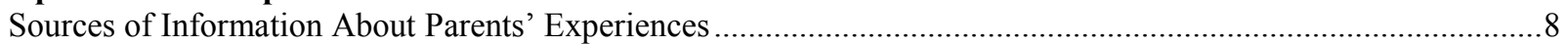

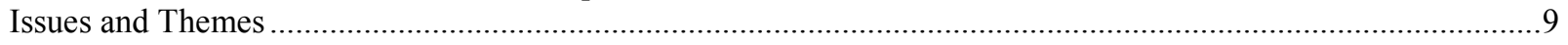

Chapter III - Service Needs and Barriers to Service Utilization ................................................................

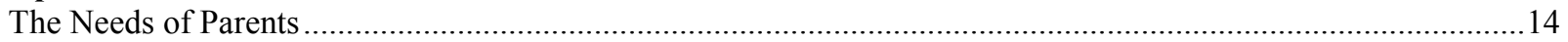

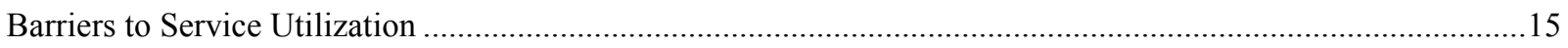

Chapter IV - Having a Parent with Mental Illness: Child Outcomes …….................................................18

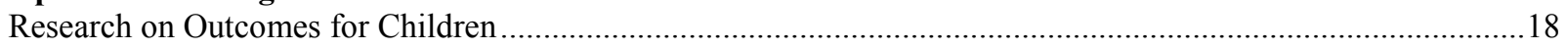

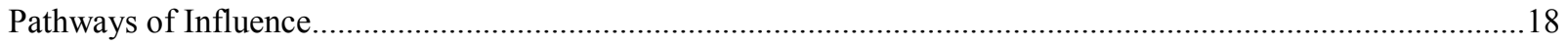

Mediators of the Relationship of Parental Mental Illness and Child Outcomes ..................................................19

Moderators of the Relationship between Parent Mental Illness and Child Outcomes .............................................22

Chapter V - Policies, Practices, and Parents with Mental Illness.................................................................26

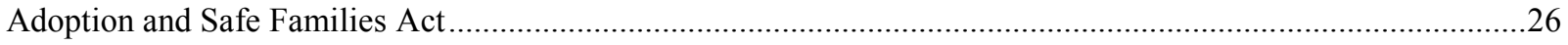

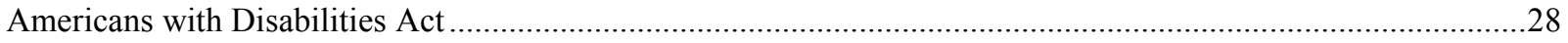

Personal Responsibility and Work Opportunity Reconciliation Act …….........................................................30

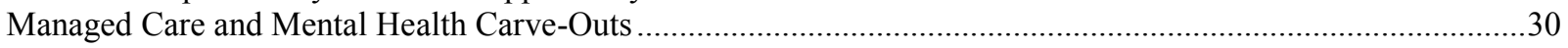

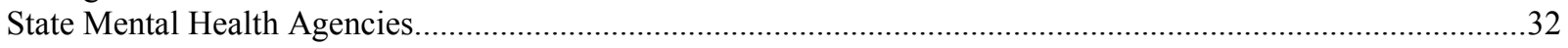

Chapter VI - What Can We Learn From Other Systems and Fields? ............................................................

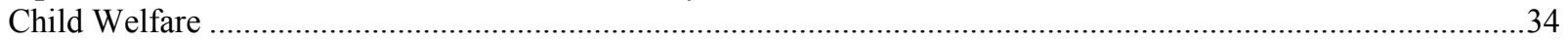

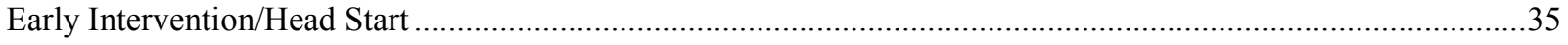

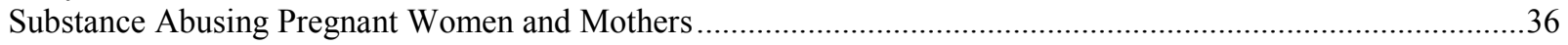

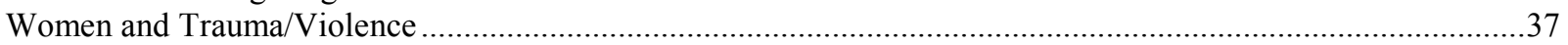

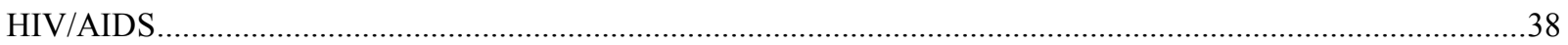

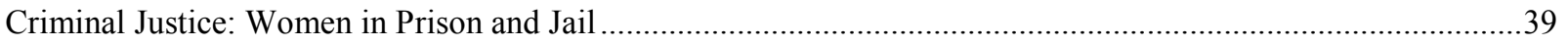

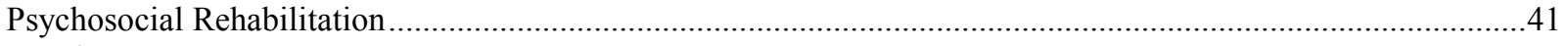

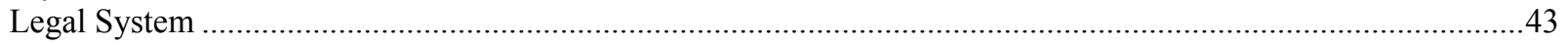

Chapter VII - Programs for Parents with Mental IIIness and their Families.....................................................45

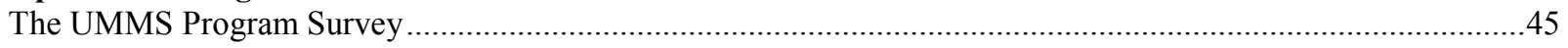

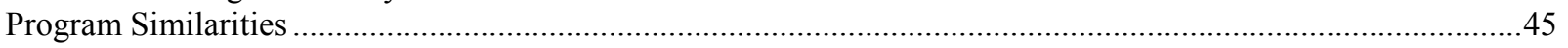

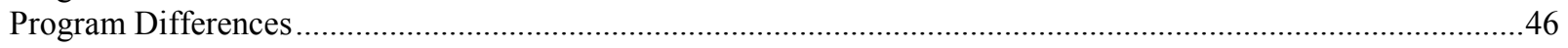

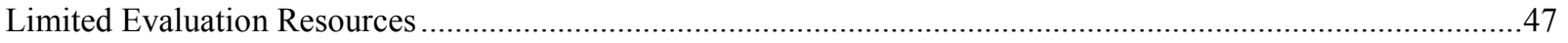

Chapter VIII - Steps for Stakeholders: A Consumer-Researcher's Perspective …..........................................49

Chapter IX - Summary of Critical Issues and Recommendations ..............................................................53

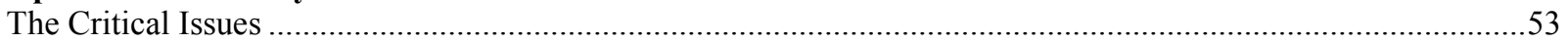

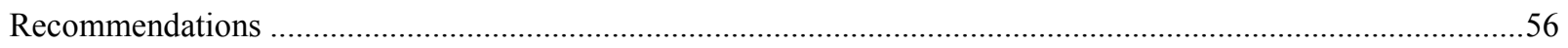

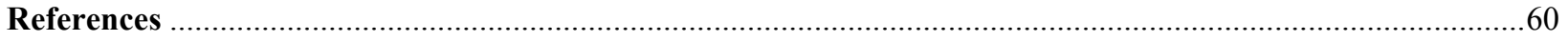

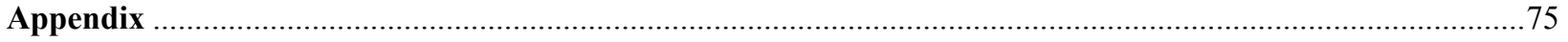




\section{Executive Summary}

\section{Introduction}

This report integrates the available knowledge regarding parents with mental illness and their families. The impact of mental illness on parenting and family life varies with the age at onset, severity and duration of the illness, and the nature of any consequent impairment in parental functioning, as well as with the strengths and resources of parents and family members. Ignorance and misinformation about mental illness, pregnancy and parenting, and the ways services are organized and policies are implemented compromise outcomes for children and adults. Innovative and promising programs are being developed to enhance outcomes for both children and parents.

\section{The Scope of the Issue}

There are no national data on the frequency with which adults with mental illness bear and care for children. Information on prevalence is drawn from existing data sets and is, therefore, limited by study rationale and methods. For example, large-scale descriptive data are not available on the characteristics of children whose parents have mental illness, such as where they are living, or in whose custody or care. Data available from the National Comorbidity Survey (NCS) indicate that:

- Almost one-third of American women and one-fifth of American men provide evidence of psychiatric disorder in the past 12 months. Sixty-five percent of these women are mothers; $52 \%$ are fathers.

- Women and men with mental illness are at least as likely, if not more likely, than those without psychiatric disorder to become parents.

- The majority of adults falling into the diagnostic categories captured by the NCS (affective disorders, anxiety disorders, PTSD, and psychotic disorders) are parents.

\section{The Experiences of Parents with Mental Illness}

Most of what we have learned in the past decade in the U.S. about the experiences of parents with mental illness is based on research with small samples of mothers in the public sector with severe mental illness and multiple stressors such as poverty and ethnic minority status. We know very little about the experiences of parents whose diagnoses fall across the full spectrum of psychiatric disorders or who are Caucasian and middle class. While the experiences of parents with mental illness are similar to those of all parents in many ways, the literature has emphasized their unique circumstances and, most commonly, their deficits and failures.

- The percent of unplanned pregnancies among women with serious mental illness is high.

- Mothers with schizophrenia have higher rates of reproductive loss, e.g., miscarriages, stillbirths, and induced abortions. 
- Parents with mental illness may be quite vulnerable to losing custody of their children, with studies reporting rates as high as $70 \%$ to $80 \%$.

- Adults with mental illness have a high likelihood of past or present victimization; symptoms associated with trauma survivorship may interfere with successful parenting.

- Parents with mental illness often feel responsible or blamed for their children's difficulties, which are more prevalent than in children whose parents are well.

- Parents with mental illness are more likely to be living without partners.

- Patterns of care giving and social support vary among ethnic and racial groups; family members may be viewed as a resource or as a source of stress.

\section{Service Needs and Barriers}

Parents and their service providers identify needs generic to all parents, as well as needs specific to their illnesses. We know very little about parents receiving services in the private sector.

- Generic needs include housing, transportation, employment, recreational activities, child care, health care, and respite from the 24-hour-a-day challenges of parenting.

- Illness-related needs include the financial and emotional resources necessary to manage symptoms, obtain services, implement treatment regimes, and maintain relationships with helping professionals.

- The stigma accompanying mental illness is a pervasive factor affecting parents' access to and participation in services.

- Services tend to be problem-focused and deficit-based rather than preventive or strengthbased.

- Funding streams and program eligibility requirements may limit participation to eligible adults or children, but not both.

- Services are not integrated or coordinated across or within systems.

\section{Child Outcomes: Having a Parent with Mental Illness}

Two decades of research indicate that children who have a parent with mental illness are at significantly greater risk for multiple psychosocial problems. Despite these risks, many children are resilient and appear to avoid significant problems. Studies have focused primarily on elaborating sources of risk, rather than identifying sources of resilience. Mental illness in parents interacts with, or is associated with many variables and processes than can enhance resilience or confer risk upon children. No attention has been paid to children's subjective experiences or reports of what is useful to them in coping with their families' circumstances. Interventions have not been widely informed by new knowledge of the contribution of moderators to enhanced child outcomes.

- Rates of child psychiatric diagnosis among offspring range from $30 \%$ to $50 \%$, compared with an estimated rate of $20 \%$ among the general child population.

- Children may show developmental delays, lower academic competence, and difficulty with social relationships. 
- Mediators or mechanisms relating parental mental illness to child outcomes include genetic influences, biological influences, illness characteristics, and environmental influences such as characteristics of parenting, marital relationships and family functioning.

- Moderators that can enhance or worsen child outcomes include spouse or partner characteristics, environmental stressors such as poverty, child characteristics, and therapeutic interventions.

It is important to note that our knowledge of child outcomes is limited by a preponderance of research that focuses on affective disorder in Caucasian, middle-class families. Consequently, our understanding of cultural and ethnic differences in the relationship between parental mental illness and child outcomes is limited.

\section{Policies and Practices}

A number of policies and practices have potential ramifications for parents with mental illness and their families.

- The Adoption and Safe Families Act (ASFA), intended to promote safety and permanency for children, imposes timelines that may be difficult for parents with mental illness to meet given the often uneven course of illness and recovery, the time needed for comprehensive family evaluation and treatment, and the lack of relevant services.

- The American with Disabilities Act (ADA) has provided little direct protection to parents with mental illness; no state has successfully called on the ADA to challenge parental rights terminations.

- Without appropriate family and work supports to overcome barriers to employment, parents with mental illness, especially single mothers, may be unable to comply with the Personal Responsibility and Work Opportunity Reconciliation Act (PRWORA/TANF) regulations, resulting in the loss of benefits to families and children in greatest need.

- Managed care organizations, including those managing public sector mental health benefits, may overlook the unique needs of their adult subscribers with mental illness who are parents in their standardized treatment authorization and utilization review processes, jeopardizing outcomes for parents and children.

- Results of a national survey of state mental health agencies indicate that attention to the needs of public sector clients as parents has become increasingly limited over the past decade. SMHAs that are unresponsive to the needs of adult clients who are parents and their children miss a prime opportunity to work towards recovery and wellness for families in the public sector.

\section{What We Can Learn From Other Systems and Fields}

- While the prevalence of certain types of mental illness in samples of known child abusers is higher than in the general population, these data do not tell us about the prevalence of child abuse or neglect in the families of parents with mental illness.

- While children in families in which parents have mental illness are likely to be at developmental risk, Early Intervention or Head Start efforts have not systematically assessed or focused upon the needs of this possibly substantial subgroup of children and families. 
- While there is most likely considerable overlap between the population of parents with substance abuse issues and those with mental illness, the knowledge gained in shifting substance abuse treatment paradigms from an individual client to a mother-child focus has not been widely applied in the mental health treatment arena.

- The high prevalence of violent victimization and trauma among women with mental illness is likely to have ramifications for those among them who are mothers. These issues are frequently not addressed in mental health assessment or treatment.

- Women living with serious mental illness are at increased risk for HIV infection, contributing to a complex set of challenges and comprehensive service needs for those who are mothers, and their children.

- Incarcerated women have higher rates of psychiatric disorders than the general population, and three out of every four incarcerated women have children.

- While psychiatric rehabilitation strategies have been shown to be effective in enhancing role participation among adults with mental illness, the parenting role has largely been ignored.

- In many states, the diagnosis of mental illness justifies the removal of children from their parents' care and the termination of parental rights. The legal determination of "parental competence" or the impact of a particular parent's mental illness on his or her capacity to parent is complicated by the lack of an accepted definition, the irrelevance of traditional psychological instruments, situational influences, and the lack of normative data.

\section{Programs for Parents with Mental Illness and their Families}

Innovative and promising programs have been developed in the U.S. and other countries over the last 20 years, though they are small in number. In areas where there are no programs designed specifically to serve parents with mental illness, providers and families may piece together a patchwork of services.

- Programs develop from the recognition that traditional services do not address the needs of parents with mental illness and their families.

- Providers share a belief in the capacity of adults with mental illness to be parents.

- The needs of families are complex and require coordination of multiple services.

- Programs share goals of (1) addressing basic needs; (2) improving parents' coping and problem-solving skills; (3) improving parenting skills specifically; and (4) enhancing child development.

- Programs are extremely diverse in services and interventions provided, and can be distinguished along two dimensions, comprehensiveness and family-centeredness.

- Targeted program outcomes differ.

- Programs have limited resources for evaluation.

\section{Steps for Stakeholders: A Consumer-Researcher's Perspective}

- Identify adults with mental illness as parents.

- Recognize the strengths of parents with mental illness.

- Battle the stigma of mental illness.

- Attend to the termination of parental rights process, custody concerns and visitation issues for parents with mental illness and their children. 
- Provide supports for children whose parents are living with mental illness.

- Educate professionals regarding the challenges and needs of parents with mental illness and their families.

- Provide peer supports for parents.

- Prioritize parenting as a policy issue.

- Coordinate services for parents.

\section{Recommendations}

\section{Systems:}

- Obtain national prevalence data on the parenting status of adults with mental illness, both fathers and mothers, and the family status of their children, for use in policy and program planning.

- Identify factors that contribute to parents' success and reduce risk to their children.

- Explore the experiences of children whose parents have mental illness in the current treatment, rehabilitation and advocacy climates, and provide opportunities for subjective reporting to children of different ages and developmental stages.

- Conduct research on the prevalence of child abuse and neglect among families in which parents have mental illness.

- Study the impact of childhood trauma and current violence on parents' functioning, their relationships with their children, and their ability and willingness to access services.

- Document the costs and benefits of family disruption (emotional and financial) and factor these into policy and practice decision-making.

- Review existing policies and practices and modify them, as needed, to consider the impact on parents with mental illness and their families.

- Reorganize the administration and funding of mental health services to support the system's capacity to respond to family need whether the "identified client" is the adult or the child, and encourage a "family wrap-around" approach.

- Support knowledge dissemination across systems and fields, e.g., child welfare family preservation models, Head Start/early intervention models, programs for incarcerated parents, substance abuse treatment initiatives, etc.

- Involve consumers and family members in all aspects of research, policy and program development and evaluation, and training and advocacy.

\section{Services:}

- Revise standardized service plans and treatment protocols to overcome system-induced barriers to service utilization and treatment effectiveness for parents with mental illness and their children.

- Modify interagency agreements and vendor contracts to permit the inclusion of language and expectations for integrated, family-centered, strengths-based care for parents with mental illness and their children.

- Describe and evaluate existing programs; replicate those that are effective.

- Support the development and evaluation of innovative intervention strategies. 


\section{Training and Advocacy:}

- Target training and advocacy efforts to policy makers, program planners and providers in all systems and domains in which families find themselves, including child welfare workers, teachers, early intervention providers, lawyers, judges, law enforcement personnel, and health care professionals.

- Educate families, parents and children about mental illness to overcome stigma among family members and in communities.

- A national advocacy network and peer supports may be essential to promoting the well being and healthy functioning of parents with mental illness and their children. 


\section{Overview}

Nearly half of the women and men in the United States report a lifetime prevalence of psychiatric disorder, and 30\% report the prevalence of at least one disorder in the previous 12 months (Kessler et al., 1997). Two-thirds of these women, and over half of these men are parents (Nicholson, Larkin, Simon, \& Banks, 2001). The impact of mental illness on parenting and family life cannot be overstated. As with any illness, the impact varies with the severity and duration of the illness, and the nature of any consequent impairment in parental functioning, as well as with the strengths and resources of the parents and children. What distinguishes mental illness from heart disease, diabetes or cancer is stigma, and the impact of being labeled with a psychiatric diagnosis on the experiences of parents and family members.

Opportunities for supporting families in which parents have mental illness are missed or lost for many reasons. Outcomes for children and adults are compromised by ignorance and misinformation about mental illness, pregnancy and parenting, and by the ways services are organized and policies are implemented. Oftentimes, providers and policy makers focus on individual patients or clients, rather than on adults with mental illness living in the context of communities and families, neglecting even to ask about an individual's family role and responsibilities (Nicholson, Geller \& Fisher, 1996; Nicholson, Geller, Fisher \& Dion, 1993). Consequently, parents' efforts are overlooked or undermined, families are disrupted, and systems are strained by the burden of providing additional services, or alternative care and placements for children who might otherwise have stayed at home.

In these situations, outcomes are compromised for children, typically considered by providers and policy makers to be "at risk" of developing problems, rather than "resilient" in the face of life challenges. The identification of negative outcomes and the prevention of psychopathology in the offspring of parents with mental illness have been the focus of research, rather than individual or contextual characteristics related to positive outcomes, or the evaluation of interventions to support family relationships. Research has demonstrated that some psychiatric disorders have an inherited component, and children whose parents have these mental illnesses may be more likely to develop similar disorders themselves (Biederman et al., 2001). However, research consistently shows that the environment in which children grow has as much, if not more, to do with their development and emotional well-being as does the genetic component (Silverman, 1989). Because outcomes for children are multiply-determined, there are many opportunities and potentially effective strategies for interventions. While there is a significant body of knowledge to inform these strategies, research often has not been brought to bear on the development of policies or practices targeted to this population.

In this report, parents with mental illness are defined as adults who have ever been diagnosed with a psychiatric disorder who have ever given birth to or fathered a child. Because of the reportedly high incidence of custody loss among these parents, particularly in the public sector, many may be parents in name only (Mowbray, Oyserman, Zemencuk \& Ross, 1995b); their children are raised by others - foster or adoptive parents, relatives or strangers. Parents may be in contact with their young children, be reunited with older children when they become adults, or be totally estranged from family members over a lifetime. Yet, they define themselves as parents rather than patients, and think about, worry about, and sometimes long for their children. Interventions with adults will fail if their parenting status, goals for themselves and 
their children, and feelings they have regarding connection, loss or reunification with family members are not considered.

Our task is to integrate the knowledge regarding parents with mental illness and their families as the first step in the Substance Abuse and Mental Health Services Administration (SAMHSA) knowledge development and application process. We delineate the scope of the problem; describe the experiences of parents with mental illness in their families, and in relation to providers and service systems; evaluate the current research on outcomes for children; outline major policy and practice issues; explore relevant findings from other systems and fields; describe interventions; and make recommendations for action by policy makers, providers, advocates, parents and family members. We address the following questions:

- Who are parents with mental illness and their families?

- What do we know about the experiences of adults with mental illness who are parents? What are their needs? What are the barriers to meeting their needs?

- What is the impact on children of having a parent with mental illness?

- How do federal, state and local policies and practices affect these families?

- What can we learn from other service systems and fields to inform our research, policies and practice?

- Are there effective program models to enhance outcomes for parents and their offspring?

- What steps can stakeholders take to promote positive outcomes for parents and children? 


\section{Methods}

Knowledge integration efforts typically begin with a review of the existing professional and popular literature. We reviewed and developed a database of over 900 articles and publications on the issues relevant to this topic. To obtain updated information on policies and programs, we conducted two surveys. The first was a structured survey directed to state mental health agency (SMHA) commissioners and directors in all fifty states and the District of Columbia regarding policies and programs for parents with mental illness and their families, and service coordination and integration issues. This survey was a follow-up to a national survey of SMHAs conducted in 1990 (Nicholson et al., 1993).

The second was a survey of programs across the country. Survey forms were mailed to a snowball sample of programs, with the initial list derived from the respondents to the original national program survey conducted in 1990 (Nicholson et al., 1993); additional names and locations drawn from a national network mailing list maintained by the Parents' Projects team at the University of Massachusetts Medical School (UMMS) Center for Mental Health Services Research; and further programs identified by sites contacted earlier in the survey process. A total of 62 programs were identified. Of these, 25 programs were determined to focus specifically on the needs of parents with mental illness and their families, and program directors were interviewed extensively by telephone using a semi-structured interview format. An additional two programs were identified through the interview process. These two programs were contacted and interviewed.

Twenty-eight key informants from eight service systems or fields were interviewed by telephone to enhance our understanding of what can be learned from other fields and perhaps applied successfully to the circumstances of parents with mental illness and their families. The informants--researchers, providers, policy makers and consumers--representing the arenas of mental health, child welfare, early intervention/Head Start, rehabilitation, criminal justice, welfare reform, the legal system and public health were interviewed using a semi-structured format for approximately one to two hours. Key informants were questioned, specific to their "arena" of interest, regarding their perspective on critical issues for parents diagnosed with mental illness and their families. Responses were analyzed qualitatively; themes were coded and grouped to form categories of concern, and to contribute to recommendations for change.

Findings from these studies were reviewed by a National Advisory Group of researcher, provider, policy maker and consumer experts gathered at the National Institutes of Health in Bethesda, Maryland, in October 1999. (See Appendix for a listing of National Advisory Group participants.) Their comments and suggestions have been integrated with our findings to address the questions outlined above. This paper, however, is not meant to represent their unique points of view, nor does it have their specific endorsements. 


\section{Chapter I}

\section{The Scope of the Issue}

CRITICAL ISSUE: There are no national data on the frequency with which adults with mental illness bear and care for children. Information on prevalence is drawn from existing data sets and is, therefore, limited by study rationale and methods. Large-scale descriptive data are not available on the characteristics of children whose parents have mental illness, such as where they are living or in whose custody or care.

\section{Who are Parents with Mental Illness?}

The number of parents living with mental illness is likely to be in the millions. Every year, $22 \%$ of the American population is affected by psychiatric disorder. About $3 \%$ of the adult population (approximately 5 million individuals in 1990) is diagnosed with severe psychiatric disorder, as indicated by diagnosis and disability (Goodwin et al., 1993). According to U.S. Census Bureau data, the majority of American women and men are parents (Bachu, 1995, 1996). The likelihood is high that many of the 5 million Americans diagnosed with severe mental illness each year, those most challenged by disability, already are or will become parents.

We reviewed findings from existing data sets, including the National Institute on Disability and Rehabilitation Research-funded National Survey of Parents with Disabilities, and the National Comorbidity Survey, to begin to address this question more carefully. These studies were not designed to describe the circumstances of families or characteristics of children in which parents have mental illness, and the usefulness of findings must be qualified.

\section{The National Survey of Parents with Disabilities}

Within populations of parents known to have disabilities, many identify themselves as having psychiatric disabilities alone, or in combination with other physical or medical disabilities (Barker \& Maralani, 1997). In the National Institute on Disability and Rehabilitation Research (NIDRR)-funded Research and Training Center (RTC) National Survey of Parents with Disabilities, data from a convenience sample of over 1,200 adults with disabilities was supplemented by a secondary analysis of the 1993 U.S. Census Bureau Survey of Income and Program Participation (SIPP; Barker \& Maralani). In the NIDRR/RTC study, one in seven parents with disabilities identified a psychiatric disability as the primary disability. According to SIPP data, about 7 million parents with children under the age of 18 have disabilities. Applying the NIDRR/RTC rate of one in seven to the SIPP data, it is possible to estimate that approximately one million parents of children under the age of 18 have psychiatric disabilities.

This, however, is a gross underestimate of all individuals with mental illness who are parents for several reasons. First, the RTC Survey focused on parents with mental illness who identify themselves as disabled as a consequence. Therefore, parents with mental illness who do not define themselves as "ill" or who do not view themselves as disabled are not represented in the study. In addition, minority populations are underrepresented in the RTC sample. The RTC survey was only distributed in English; data were not obtained in other languages. The RTC sample also had a higher percentage of female, white, highly educated respondents than the U.S. Census Bureau SIPP data. Finally, the data do not include information about parents who do not have custody, those with children who are adults themselves, or those with children living in alternative family situations. 
Mothers with mental illness, more frequently studied than fathers, have numbers of children consistent with the general population (Caton, Cournos \& Dominguez, 1999; Mowbray et al., 1995b; White, Nicholson, Fisher \& Geller, 1995). Therefore, extrapolating from the NIDRR/RTC data convenience sample estimate of about one million parents with psychiatric disabilities whose children are under the age of 18, at least two to three million children in American have parents with self-reported psychiatric disabilities. In the NIDRR/RTC data, nearly half of the children of parents with psychiatric disabilities have disabilities themselves, underscoring the importance of supports for children as well as adults, and the potential impact of improving parents' skills on the lives of millions of children. These data highlight the significance of considering families, rather than individual adults or children, as the client "unit."

\section{The National Comorbidity Survey}

Recently, data from the National Comorbidity Survey (NCS) of the United States, a survey of a national probability sample of over 8,000 respondents carried out between 1990 and 1992 by Dr. Ronald Kessler and colleagues, have become available for analysis regarding parenting issues and mental illness (Kessler, 1994). Demographic data from these respondents have been shown to be comparable to U.S. Census distributions (Kessler), suggesting that conclusions drawn from NCS data are likely to be generalizable to the larger U.S. population. In Phase II of the NCS, interviews were administered to 5,877 respondents, and included items on parenting and children, allowing preliminary findings on the rates at which individuals with psychiatric and/or substance abuse disorders, in various diagnostic categories, become parents.

Recent preliminary analyses of National Comorbidity Survey data regarding the prevalence of mental illness and parenting indicate that about $31 \%$ of American women and about $17 \%$ of men have a 12-month prevalence of at least one psychiatric disorder (not including substance abuse), and significant percents of these individuals are mothers (65\%) and fathers $(52 \%)$ (Nicholson et al., 2001). The NCS data suggest that women and men with psychiatric disorders or with co-occurring psychiatric disorders and substance abuse may be at least as likely if not more likely to be parents than those who do not meet criteria for psychiatric disorder or substance abuse.

Among women in the NCS sample who are mothers, $25 \%$ meet criteria for diagnoses in the affective disorder category, including major depression, mania, bipolar disorder and dysthymia. Approximately one-third of the NCS women who are mothers have a lifetime prevalence of anxiety disorders. Slightly over 11 percent meet criteria for post traumatic stress disorder, and less than one percent for a nonaffective psychosis disorder diagnosis.

Among men in the NCS sample who are fathers, almost one-sixth have a lifetime prevalence of affective disorders. About one-fifth have anxiety disorders. Approximately six percent meet criteria for post traumatic stress disorder, and fewer than one percent have a lifetime prevalence of nonaffective psychosis.

Unfortunately, it is impossible to describe the current family circumstances of adults who participated in the NCS in detail, other than to know they have had children. Information about the prevalence of custody loss among parents with mental illness, the frequency with which children require alternative caregiving when parents' functioning is compromised by illness, or the percent of children relinquished for adoption or raised by others is not available.

\section{Public Sector Data}

Available data from public sector management information systems sources, such as state mental health agency case management records, indicate a significant percent of adult clients 
receiving public sector mental health services are parents. Data from the New York State Office of Mental Health indicated that $45 \%$ of women under the age of 35 receiving intensive case management services have children, and of these, $20 \%$ are identified as the custodial parent (Blanch, Nicholson \& Purcell, 1994). Analyses of Massachusetts Department of Mental Health (MA/DMH) case management rosters in the early 1990's indicated that approximately $9 \%$ of the total MA/DMH client population of adult women with serious and persistent mental illness were identified as having dependent children (White et al., 1995).

The knowledge gained from existing sources like these is routinely compromised by "sampling error," and deficits in the questions asked. For example, prevalence estimates culled from public sector mental health systems sources represent the sub-sample of adults diagnosed with mental illness who are in greatest need, who meet eligibility criteria regarding severity and duration of illness and functional impairment and, oftentimes, additional criteria such as multiple hospitalizations or homelessness. It is difficult to generalize from these data to the general population of individuals with mental illness that includes those receiving services in the private sector, or those not receiving services at all.

Often the right set of questions is not asked. For example, in completing the MA/DMH client tracking forms from the early 1990's, which have since been revised, the case manager checked a box if a client was known to "have a dependent child." This category was defined as "client is the primary caretaker for a minor child." First, a check in this box was based on the case manager's knowledge of the client's parenting status and history. Second, a check reflected knowledge only of those with children under the age of 18, with whom the adult was actively involved. Therefore, information was not recorded about children ever born who might be adults themselves, or those who might be living independently or in alternative family situations with relatives, foster parents or adoptive parents. In addition, information was not routinely obtained about pregnancy status or whether adults were considering becoming pregnant.

It is important to note that Massachusetts was not alone, by any means, in overlooking this information. In our original survey of SMHAs, conducted in 1990 and 1991, only 16 SMHAs routinely asked whether clients were parents (Nicholson et al., 1993). This state-level oversight is repeated at the clinical level in inpatient and outpatient psychiatric settings, where records do not contain this information (DeChillo, Koren \& Schultze, 1994; Rudolph, Larson, Sweeny, Hough \& Arorian, 1990). Information is not routinely obtained about whether adults with mental illness have even given birth to or fathered a child, the ages of these children, where they are living, or who is caring for them. And yet the likelihood that parents comprise a significant percent of inpatient or outpatient populations is high.

In Massachusetts, clinicians completed surveys at three sites - a Massachusetts Department of Mental Health case management site, the outpatient department of a community mental health center site, and a site providing both case management and outpatient treatment services (Nicholson, unpublished raw data). The percent of female outpatient clients who are mothers ranged from $33 \%$ to $50 \%$. Twenty-one percent of male clients are known by clinicians to be fathers (Nicholson, Nason, Calabresi \& Yando, 1999). The average number of children born to each parent is a little over two, suggesting these families are similar to the national average. Again, these prevalence figures must be considered underestimates as they are data obtained from clinicians, not the clients themselves, and these sites serve the small slice of the population diagnosed with severe and lengthy illnesses.

While individual states and agencies have modified forms and procedures to begin to collect this information, our recent survey of state mental health agencies, conducted in 1999 , 
indicates that an even lower number of SMHAs (12) than the number in 1990 (16) are collecting this information on a routine basis. While SMHAs may justify this lack of data collection by pointing to the privatization of the case management function, or as the responsibility of managed care organizations and providers, this abdication of responsibility robs the SMHAs of opportunities to promote quality care through the development of relevant policies, regulations, procedures, and services. Adequate policy development, program planning or clinical care, to address the issues and meet the needs of adults with mental illness and their children, cannot occur without accurate prevalence data, and more detailed information about the circumstances, goals and needs of these families.

SUMMARY: There are no national data on the prevalence of adults with mental illness becoming parents and raising children, nor do data exist describing their children. Efforts to extrapolate these figures from existing data sets or community clinic sites are limited by the types of questions asked and populations served. Parents with mental illness are not routinely asked comprehensive questions about their family or household circumstances. Therefore policies and programs have not necessarily been developed with adequate information to meet the needs or goals of adults with mental illness as parents or the needs of their children. We know nothing about the prevalence of parents with mental illness in the private sector, nor about parents who are undiagnosed or not receiving treatment. Likewise, we know nothing about their children's circumstances or needs.

RECOMMENDATIONS: Adults with mental illness must be asked the "right" set of questions regarding their status as parents and their family circumstances. For example, women and men must be asked whether they have ever given birth to or fathered a child; the dates of birth and genders of their children; where their children are living; and who is caring for them. Adults with mental illness may be caring for adopted children, stepchildren or the children of others in informal arrangements as well. The issue of who has custody of children is a distinct question from the question of where children are living, who is caring for them, or the extent or nature of contact or involvement their parent with mental illness has with them. Policy makers and service providers must also ask about adults' wishes or goals for parenting, as they may differ from their current family situations. Adults' goals should be respected in service planning, as they affect adults' compliance with treatment recommendations, and outcomes for both parents and children. Children's circumstances and needs must be explored and documented. 


\section{Chapter II}

\section{The Experiences of Parents with Mental Illness}

CRITICAL ISSUE: Most of what we have learned in the past decade in the U.S. about the experiences of parents with mental illness is based on research with small samples of mothers in the public sector with severe mental illness and multiple stressors such as poverty and ethnic minority status. We know very little about the experiences of parents whose diagnoses fall across the full spectrum of psychiatric disorders across the life span, or those who are Caucasian and middle class. While the experiences of parents with mental illness are similar to those of all parents in many ways, the literature has emphasized their unique circumstances and, most commonly, their deficits and failures. Parents with mental illness must cope with reproductive issues, custody loss, and past and present victimization, oftentimes without family support. They worry about the impact of their mental illness on their children.

\section{Sources of Information About Parents' Experiences}

What is known about a phenomenon is influenced by the sources of information about the phenomenon. Unfortunately, little of what is widely understood about parents with mental illness is based on research. Most of what the public knows about parents with mental illness appears in newspaper accounts of tragic events in which children are severely injured or killed. People who abuse or neglect their children must be "crazy," according to common logic. Therefore, the general public assumes parents who are "crazy," that is, diagnosed with mental illness, probably abuse or neglect their children. What we do know about these high profile incidents is that they are, fortunately, rare. What we do not know is how many parents with mental illness are successfully raising children and participating in family life without incident.

The stories of adult "children" are another common source of information about parents with mental illness in the popular and professional literature. (See, for example, Frankel \& Hewill, July 24, 2000, People Magazine, "Surviving a Mentally Ill Mother"; Marsh, 1996) The list of negative consequences of having a parent with mental illness, culled from the retrospective reports of adult children is lengthy and includes: anger, isolation, shame, fear, sadness, chaos, grief, neglect, feelings of helplessness, frustration, and confusion, identity problems, poor self-esteem, and trust and intimacy difficulties (Marsh, Appleby, Dickens, Owens \& Young, 1993). However, adult children describe positive consequences as well, reflecting the development of resilience in the face of family difficulties: strength, empathy and compassion, tolerance and understanding, healthy attitudes and priorities, and an appreciation of life (Marsh et al.). Many adult children report living through very difficult situations during times, in years past, when the stigma surrounding mental illness precluded open family discussion or education; "disappearances" from the home, that is, parents' hospitalizations, were lengthy and unexplained; and treatments were less effective. The stories are yet to be told of children growing up in times when parents are more open in discussing their illnesses; hospitalizations are planned and shorter in duration; and treatments and rehabilitation provide increased hope of recovery.

In the past decade, researchers and providers have become more interested in the experiences of adults with mental illness who are parents. A growing number of studies have focused on the description of parents with mental illness, their circumstances, i.e., stressors and resources, and their service needs. However, findings are limited in generalizability, given the 
characteristics of studies and study participants. Studies in the U.S. over the past 10 years have, for the most part, involved small samples of women recruited in hospital, clinic, or other treatment settings (Joseph, Joshi, Lewin \& Abrams, 1999; Miller, 1990; Miller \& Finnerty, 1996; Mowbray et al., 1995b; Nicholson, Sweeney \& Geller, 1998a, 1998b; Rogosch, Mowbray \& Bogat, 1992; Rudolph et al., 1990; Sands, 1995; Zemencuk, Rogosch \& Mowbray, 1995). A smaller number of studies have drawn larger samples from pools of existing data (Gamache, Tessler \& Nicholson, 1995; Kelly et al., 1999; White et al., 1995), or clinic (Mowbray et al., 2000) or rehabilitation center populations (Ritsher, Coursey \& Farrell, 1997). Nicholson and colleagues (1999), in the only published study of fathers, reported data on a sample of clinic clients. The vast majority of these recruitment settings or databases, to the extent we can determine from reading the literature, are public sector settings or rosters. Studies have been cross-sectional in design and descriptive in nature.

Study participants, for the most part, have been women with serious mental illness, as distinguished by diagnosis, illness duration, or hospitalization status. The majority of women, in the vast majority of these studies have diagnoses of psychosis, schizophrenia, schizoaffective disorder, or are described as having chronic or severe mental illness. Women with affective disorders outnumbered those labeled with psychotic disorders in only two samples (Nicholson et al., 1998a, 1998b; White et al., 1995), even though, judging from the NCS prevalence data previously cited, mothers with affective disorders far outnumber those diagnosed with psychotic disorders.

The background characteristics of women study participants limit the generalizability of the findings. The majority of women (from 55\% to 70\%) in seven of the 14 studies are AfricanAmerican; in 4 of the studies they comprise from $6 \%$ to $39 \%$ of the participants. The remaining three study samples are described as ethnically and racially "diverse." In most studies, the majority of women are divorced, separated, or never married, i.e., single parents. In eight of the studies the percents of women never married or not living with the father of their children are above $50 \%$, ranging from $51 \%$ to $82 \%$. In studies in which employment status or socioeconomic status (SES) are indicated, most mothers fall into the unemployed or low SES categories. Given the public sector settings from which study participants are recruited, it seems plausible that most of these mothers are poor.

\section{Issues and Themes}

The experiences of parents with mental illness are similar to those of all parents in many ways. Parents with mental illness routinely describe their relationships with their children and fulfilling the parenting role as extremely important to them (Nicholson et al., 1998a). They may prioritize their children's needs, and neglect their own (Nicholson et al.) They may struggle to fulfill multiple role demands, and experience stress as they maintain a household, cope with the demands of work, and manage the behavior and activities of their children. Their marriages and family life may suffer under these circumstances, just as those of parents living without mental illness. However, parents with mental illness are prone to interpreting their difficulties managing the stresses of everyday life as illness-related personal deficits, rather than simply the "normal" stress of too much to do, judging themselves harshly against unrealistic standards and falling short (Nicholson et al.). 
Pregnancy. Pregnancy brings a unique set of challenges to adults living with mental illness. The percent of unplanned pregnancies among women with serious mental illness is high (Miller, 1990; Ritsher et al., 1997). Mothers with schizophrenia have higher rates of spontaneous miscarriages, stillbirths, and induced abortions (Coverdale, McCollough, Chervenak, Bayer \& Weeks, 1997; Miller, Resnick, Williams \& Bloom, 1990). Psychotic denial of pregnancy happens with greater frequency in women who have previously lost custody of children (Miller).

Women with mental illness who are uninformed about issues of psychotropic medication and pregnancy, may stop taking their medications unnecessarily, thinking they are protecting the fetus. Clinicians are advised to make decisions regarding medication jointly with pregnant women (Empfield, 2000). A pregnant woman with schizophrenia may be maintained on a dose of antipsychotic that will not negatively impact her infant (Altshuler \& Szuba, 1994). ECT has been suggested as a treatment option for pregnant women with severe depression (Miller, 1994).

Custody and Experiences of Loss. The literature suggests parents with mental illness are quite vulnerable to losing custody of their children, with custody loss rates in some studies as high as $70 \%$ to $80 \%$ (Joseph et al., 1999; Mowbray et al., 1995b). Rates of custody loss may vary by diagnosis; women with affective disorder diagnoses are more likely to be primary caregivers than women with psychotic disorder diagnoses (White et al., 1995). This finding is corroborated by Miller and colleagues, who indicate that children of women with schizophrenia are more likely to be raised by someone else (Miller, 1997; Miller \& Finnerty, 1996). In Joseph and colleagues' study, the majority of mothers felt it was very important to continue to help raise their minor children, even though only $21 \%$ of the mothers had custody, and only $12 \%$ had primary responsibility for childrearing.

Maintaining relationships when children are living with relatives or in foster care may be difficult (Nicholson et al., 1998b). Visits may be stressful to both parent and child, particularly if not well planned or managed. Parents may experience their children's divided loyalties when children are split between family members or homes. They may feel angry or jealous when their children call others "mommy" or "daddy." Children may express anger to parents about their current living situations. Visits may be painful for parents and children who reminded of their losses each time a visit ends.

Separations may undermine parents' recoveries, particularly if children are placed with grandparents or other relatives who are known by parents to have been abusive in the past. Mothers with mental illness describe themselves as needing help getting their children returned to them, and in dealing with sadness about being apart from their children (Joseph et al., 1999). Parents explain that when their parental rights are terminated, the pain never goes away (Nicholson et al., 1998a). To fail as parents may be quite traumatic.

Victimization and Trauma. Researchers and providers are becoming aware of the high likelihood that adults with mental illness have histories of childhood abuse or are exposed to current violence (Goodman, Rosenberg, Mueser \& Drake, 1997). The prevalence of victimization among samples of women with serious mental illness in published studies ranges from 53 to 97\%. Having been abused as a child does not necessarily result in being an abusive parent. In fact, having been abused may motivate a parent to treat his or her own children differently (Nicholson, 1998 presentation). Other phenomena that co-occur with both victimization and serious mental illness, however, such as poverty, substance abuse, and 
homelessness, may have serious implications for safe parenting, and may increase risks to children and parents. It may be difficult to tease out the influence of each to the overall risk a family faces.

Symptoms associated with trauma histories may interfere with successful parenting (Nicholson, 1998 presentation). Children develop ways of coping with trauma to survive. For example, children exposed to repeated trauma such as sexual abuse may learn to depend on avoidance or withdrawal to deal with stress. These "survival skills," however, may mitigate against healthy adult functioning; they may come to be framed as the symptoms of posttraumatic stress disorder. As adults, victims of childhood violence may have difficulty with trust and intimacy in relationships; may develop coping mechanisms that mitigate against emotional and physical safety, such as substance abuse or sexual acting-out; may have issues related to "power" and feelings of "powerlessness;" may have dissociative or "numbing" episodes; and may have feelings of low self-esteem, guilt, and shame (Harris \& Landis, 1997).

While these coping strategies or "symptoms" may have kept victims of childhood abuse alive, they may affect an adult's capacity to parent effectively. For example, mothers may have difficulty trusting their own assessments of their children's needs and their ability to meet them, and difficulty building relationships with helping professionals. They may need support to establish a physically and emotionally safe home environment for their children if they have never experienced a safe home environment themselves. If parents have been disempowered by their victimization experiences, or the stigma that is associated with victimization or a consequent diagnosis of mental illness, they may have difficulty advocating for themselves or their children. Children's developmental stages or ages, or their particular experiences may remind parents of unpleasant times in their own past, and may actually trigger parents' flashbacks, or contribute to parental anxiety or depression. For example, mothers who were victimized in the bathroom when they were children may have difficulty bathing or toilet training their own children (Nicholson, 1998 presentation).

Parents Worry About Their Children. Many children of parents with mental illness do not have abnormal difficulties (Beardslee \& Poderofsky, 1988). However, parents worry about the impact of their mental illness on their children, and may view children's "normal" behavior through the lens of their illness (Nicholson et al., 1998a). They may be concerned that any signs of misbehavior or distress on their children's parts are signs of developing emotional disturbance in the younger generation. If parents had impoverished or abusive childhoods themselves, they may not have realistic expectations regarding children's development or behavior, or may not have ideas about how to stimulate their children's development through play. Parents, therefore, may not only need psychoeducation regarding their own mental illness, but information about normal child development, and feedback that their children's behavior is age-appropriate and to be expected (Nicholson et al., 1998a).

Parents with acknowledged psychiatric disabilities report almost $50 \%$ of their children have disabilities as well (Barker \& Maralani, 1997). These children may have emotional or behavioral issues requiring appointments with treatment providers or medication. Parents, therefore, may have to manage their children's treatment regimes as well as their own. They may prioritize their children's special needs, making sure their children participate in counseling appointments, but neglect their own service needs if time, energy or money are in short supply (Nicholson et al., 1998a). Parents with mental illness often feel they have to prove themselves, 
and feel blamed or responsible for their children's difficulties, whether they fall within the range of "normal," or are extreme enough to require special attention.

Family Relationships and Social Networks. There are positive as well as negative aspects to family relationships for parents with mental illness. Family members may be a primary source of social support, and a buffer against stress. Fifty-five percent of the women in Ritsher et al.'s study (1997) indicated they have at least one family member who is supportive, and $61 \%$ feel fully accepted as a member of the family. Mothers, however, describe feeling disempowered when grandparents or other relatives make decisions about children's schooling or medical care without consulting them (Nicholson et al., 1998b).

While parents with mental illness are more likely to have ever been married than adults with mental illness who are not parents, they are also more likely to be living without partners (Mowbray et al., 2000; White et al., 1995). Women with schizophrenia are less likely to be married or living with a partner when their children are born (Miller, 1997; Miller \& Finnerty, 1996). Mothers explain husbands or partners, in fact, may be resources or stressors, e.g., assisting with childcare and household tasks or undermining women's efforts to parent and/or recover from illness (Nicholson et al., 1998b). In Mowbray and colleagues' study, children's fathers were one of the hassles rated highest by mothers (Mowbray et al.). While single parents may be isolated and without supports, the addition of a partner may not always be a positive factor.

Many mothers with mental illness rely on relatives or friends for child care assistance (Hearle, Plant, Jenner, Barkla \& McGrath, 1999, Nicholson et al., 1998b). Patterns of caregiving and social support vary among ethnic and racial groups, with mothers of color with mental illness more likely to be primary caretakers than Caucasian mothers (White et al., 1995). Mothers caring for children have been found to have better immediate and extended social networks (White et al.). As these data are cross-sectional, it is not clear whether mothers with better social networks are more likely to retain custody of their children, or whether caring for children provides increased opportunity to develop social networks.

SUMMARY: Much of what the public knows about parents with mental illness is not empirically-based. Most research on the experiences of parents with mental illness has focused on small samples of mothers, recruited in public sector treatment settings, who are diagnosed with serious mental illness (primarily psychotic disorders), are African-American, parenting without partners, and poor. While findings from these studies may not be generalizable to the larger population of parents with mental illness, they certainly tell us a great deal about the families most likely to be at greatest risk, and in greatest need of services, particularly public sector mental health services.

While the experiences of parents with mental illness are similar to those of all parents in many ways, the literature has emphasized their unique circumstances and, most commonly, their deficits and failures. Parents with mental illness face particular challenges in pregnancy, and suffer higher rates of reproductive crisis. They are vulnerable to losing custody of their children, and often must cope with the pain of separation and loss. They are likely to be survivors of violence and victimization, with consequences for their functioning as adults and as parents. They worry about their children, and often feel responsible or blamed for their problems. Patterns of support and care giving most likely vary among ethnic and racial groups; family members may be viewed as a resource or a source of stress. 
RECOMMENDATIONS: More research is needed on the broad spectrum of parents with mental illness - mothers and fathers--from all walks of life, i.e., varying racial and ethnic groups, socioeconomic classes, diagnostic categories, marital statuses, receiving public or private sector services, etc., across the life span. There has been only one published study of fathers with mental illness - clearly an overlooked population. Longitudinal studies could focus on the impact of parenting on mental illness, as well as the impact of mental illness on parenting.

The existing research on the common issues and themes identified by parents with mental illness suggests many opportunities for ameliorative and preventive intervention for both parents and families. Potential intervention targets include reproductive decision-making and perinatal health care; dealing with custody loss, visitations and placements; mitigating the impact of past and present violence on current functioning and relationships; understanding normal child development and how to stimulate and play with children; building a repertoire of child behavior management skills; and developing supportive family support and social networks. These targets are not necessarily specific to parents with mental illness. Successful intervention strategies build on strengths, rather than focus on deficits. 


\section{Chapter III}

\section{Service Needs and Barriers to Service Utilization}

CRITICAL ISSUE: Parents with mental illness have needs common to all parents, as well as needs specific to their illnesses. The stigma of mental illness and the pervasive assumption that parents with mental illness will fail keep many parents from seeking help. Parents may appear to be non-compliant with service plans that are deficit-based or do not consider their unique needs as parents. Existing services may be irrelevant to the specific needs of these families, or fragmented due to organizational issues and funding streams.

\section{The Needs of Parents}

Parents with mental illness and their service providers identify a set of needs and challenges generic to all parents (Cook \& Steigman, 2000; Mowbray et al., 2000; Nicholson \& Henry, in press; Nicholson et al., 1998a, 1998b). These include: access to safe, affordable housing; transportation; employment, or educational or vocational training opportunities; access to benefits and entitlements when work is not possible; low-cost or free recreational activities for families; safe, dependable child care; adequate health care; support for learning parenting skills; trusted respite care for children, when parents need to be hospitalized or take a break from parenting responsibilities; and support for advocating for themselves and their children's needs, particularly with the school system (Nicholson \& Henry).

While these challenges may be similar to those of other parents in nature, they may differ in degree. Mowbray and colleagues, in their study of mothers with mental illness in Detroit, indicate that neighborhood safety is a worry for many; unemployment rates are extremely high; physical health is rated poorly; and mothers report a high frequency of stressful life events and hassles, such as psychiatric and financial crises, death of a close friend or relative, and separation from children (Mowbray et al., 2000). While these are common problems among poor families, the unemployment rate of these Detroit mothers with mental illness is four times that of women in the same census tracts, suggesting that living with mental illness plays a role above and beyond that of poverty alone.

Parents also face challenges specific to their illnesses, which alter their experiences as parents and influence their relationships with their children. Managing symptoms and taking steps essential to recovery may drain individual and interpersonal resources. For example, obtaining services, implementing treatment regimes, and maintaining relationships with helpers require time and energy. Parents with mental illness often must advocate for themselves and their children to obtain necessary services and supports, and deal with the access challenges inherent in the "managed care" era. Parents with mental illness face the additional, illnessrelated challenges of understanding the impact of their illness on their children, and communicating with their children about their illness and recovery.

Some of these needs may be met in the mental health service system. In the above mentioned study of mothers in Detroit, the vast majority were receiving mental health services, which they found "somewhat helpful"'(Mowbray et al., 2000). While about 44\% listed their mental health provider as a source of support, only $20 \%$ of the mothers listed their mental health provider as someone who could be supportive about being a mother. In the past, research has shown that parenting services are more often provided through the child welfare system (Nicholson et al., 1993). However, mothers may view child welfare case workers quite 
negatively (Mowbray et al.; Nicholson et al., 1998a). In Mowbray's study, nearly $40 \%$ of the mothers gave child welfare case workers one of the highest hassle ratings, which the researchers attribute to mothers' long-standing concerns about losing custody of their children and more recent fears about being taken off welfare.

Mothers with mental illness in focus groups also talk about what their children need: nurturance, discipline, encouragement to develop their talents and interests, positive role models and friends, a dependable home environment, safe places to go away from home, to feel "regular" or "normal" like other families, open communication with their parents, and to understand that they are not responsible for their parents' illnesses, nor are they responsible for "fixing" them (Nicholson \& Henry, in press).

\section{Barriers to Service Utilization}

Mothers have identified problems with, and barriers to programs and services (Nicholson, 1996). The single most pervasive factor affecting parents' access to and participation in services is the stigma accompanying mental illness. Mothers are affected by their anticipation of, or actual experiences of, the negative attitudes of providers and family members. Women may hide their pregnancies from providers, fearing negative comments and the potential loss of custody (Empfield, 2000; Nicholson et al., 1998a). Obviously, prenatal care is jeopardized. Pregnant women with schizophrenia are not likely to receive obstetric consultation until their third trimester of pregnancy, nor to keep follow-up obstetric appointments after discharge from inpatient psychiatric care (Miller et al., 1990).

Stigma and assumptions about individuals with mental illness may lead providers to the conclusion that adults with mental illness are not parents or cannot parent successfully. Therefore, adults' goals regarding parenting and caring for their own families may not be identified or addressed by providers. The primary concern of adult providers is who will care for the patient, not whether the patient will be caring for someone else (Nicholson et al., 1993). Lack of attention to adults' goals as parents decreases the likelihood of their involvement in programs or compliance with treatment recommendations (Oyserman, Mowbray \& Zemencuk, 1994).

The stigma of mental illness ultimately translates for parents into the fear of custody loss particularly because of the assumptions made by society at large about individuals with mental illness, i.e., that they are incompetent, violent or potentially dangerous. Fear of losing custody can keep parents from acknowledging problems and requesting services (Hearle et al., 1999; Nicholson, 1996). Worry about losing custody or contact with children can contribute to parents' stress (Nicholson et al., 1998a). The removal of a child from a parent's care may undermine a parent's motivation to recover, and may contribute to decompensation. A focus on deficits and the assumed or real inadequacies of parents with mental illness, rather than their strengths, contributes to a cycle of hopelessness and a view of the "helping" relationship as adversarial (Nicholson \& Henry, in press).

If treatment plans are made without considering the adult's goals, identity or responsibilities as a parent, the adult may appear to be non-compliant with recommendations. For example, mothers who need to get up early to fix breakfast and send their children off to school may not take medications that make them lethargic in the morning (Nicholson et al., 1998a). Mothers who have not identified acceptable respite care for their children may resist hospitalization. A parent's recovery may be jeopardized if she is not allowed contact with or provided information about her children when she is hospitalized, or when her children are in foster care. 
Parents with mental illness view typical parenting programs as irrelevant, inappropriate or uncomfortable (Nicholson, 1996). While parent skills training interventions, for example, may offer strategies for managing children's behavior, the issues of setting limits and doling out consequences when a parent is feeling distracted, fatigued or worthless because of a mental illness are not addressed. And traditional programs for adults with mental illness do not appear to deal with the issues of parents. For example, ACT or PACT case management services do not routinely encompass the needs of adults as parents, though the model could certainly be adapted. Parenting is not mentioned as an issue in community living (McGrew, Wilson \& Bond, 1996), nor are variables related to parenting typically included as ACT outcomes (Mueser, Bond, Drake \& Resnick, 1998).

Services may not be culturally relevant. Significant differences among racial and ethnic groups in patterns of care giving when mothers have serious mental illness suggest that parents of different racial and ethnic membership have unique strengths and needs, requiring specific interventions and supports (Gamache et al., 1995; White et al., 1995). Not only may the acknowledgment, understanding, and impact of mental illness on families vary with race and ethnicity, but race and ethnicity themselves are known to be barriers to service access (U.S. Department of Health and Human Services, 2000a).

Services for parents and children may be fragmented (Blanch et al., 1994). Funding streams, and program eligibility requirements may limit participation to eligible adults or children, but not both. Services for adults and children may be provided in different locations. Programs or treatment settings may not allow adults with children to participate, e.g., emergency shelters or residential programs. Prevention services for adults and children in these families are rare. Children whose parents have mental illness, who might benefit from prevention services, may not be eligible for services because they do not have diagnosable conditions, i.e., there is no demonstrable "medical necessity." Parenting services in the public sector may be available only through the child welfare system; a parent may have to be determined abusive or neglectful to be eligible (Nicholson et al., 1993).

Cook and Steigman (2000) summarize a set of principles for working with parents with mental illness and their children. These include:

- Ongoing availability of services;

- Family must be the focus of service delivery;

- A service mix of treatment, rehabilitation, and support;

- Sensitivity to stigma associated with mental illness and prejudices faced by parents with mental illness;

- The importance of custody concerns;

- Parenting serves as the foundation for a parent's recovery; and

- Interagency collaboration.

Comprehensive services for parents with mental illness include an assessment of parenting strengths and needs; case management; peer support, self-help and parent mentoring; medication management; birth control counseling, pregnancy decision-making and support; crisis and respite care; foster care support and linkage; trauma and abuse counseling; substance abuse treatment; marital and family counseling; housing and supports for independent living; child development and parent skills training; assistance with school issues; advance directive planning and support; and benefits and public entitlement counseling (Cook \& Steigman, 2000). 
SUMMARY: Parents with mental illness have needs common to all parents as well as needs specific to their illness. The stigma attached to mental illness is a significant barrier to service utilization for parents with mental illness and their families. Adults with mental illness may not be asked about their goals or role as parents. Services are deficit-based, oftentimes available only when parents or children have diagnosable problems or when abuse or neglect have been documented. Differing patterns of caregiving across racial and ethnic groups strongly underscore the need for culturally relevant services. Services are fragmented, with seemingly arbitrary barriers existing between systems and within systems, e.g., the mental health and child welfare systems, and "adult" and "child" mental health services.

RECOMMENDATIONS: The general public, providers, and families need to be made aware of and educated about the issues and strengths of parents with mental illness. Values and attitudes regarding parents with mental illness need to be clarified in professional training programs. Services must be developed that are relevant to the needs of parents and families, and that are family-centered and strength-based. "Adult" and "child" services must be integrated across and within systems to reduce service fragmentation or duplication, and to ensure that services are as accessible and as effective as possible. 


\section{Chapter IV}

\section{Having a Parent with Mental Illness: Child Outcomes}

CRITICAL ISSUE: Research indicates that children who have a parent with mental illness are more likely to develop psychosocial difficulties. Studies, however, have focused primarily on elaborating sources of risk, rather than identifying sources of resilience. Mental illness in parents interacts with, or is associated with many variables and processes that can confer risk upon or enhance the resilience of children. No attention has been paid to children's subjective experiences or reports of what is useful to them in coping with their families' circumstances.

\section{Research on Outcomes for Children}

Two decades of research have unequivocally indicated that children who have a parent with mental illness are at significantly greater risk for multiple psychosocial problems (Beardslee et al., 1996a; Canino, Bird, Rubio-Stipec, Bravo \& Algeria, 1990; Oyserman, Mowbray, Meares $\&$ Firminger, 2000). Studies have noted rates of child psychiatric diagnosis among offspring ranging from approximately 30\% to 50\% (Canino et al.; Oyserman et al.), as compared to an estimated rate of $20 \%$ among the general child population (Friedman, Katz-Leavy, Manderscheid, \& Sondheimer, 1996). These same children are more likely to show developmental delays, lower academic competence, and difficulty with social relationships (Barocas, Seifer, \& Sameroff, 1985; Oyserman et al.; Sameroff \& Seifer, 1983; Weintraub \& Neal, 1984). Despite these risks, many children of parents will mental illness are resilient and appear to "avoid" significant problems (Beardslee \& Poderofsky, 1988).

Why do some children exposed to parental illness do well while others struggle? Active research in the area has revealed that mental illness itself does not guarantee poor outcomes. Instead, mental illness in parents interacts with, or is associated with many variables and processes that can enhance resilience or confer risk upon children (Downey \& Coyne, 1990; Goodman \& Gotlib, 1999). Thus, there are many potential avenues for intervention, and research is beginning to turn its attention to these important issues.

It is important to note that the research on child outcomes has been limited in several ways. The majority of studies have focused on white, middle-class families in which the mother has an affective disorder diagnosis. Thus, our understanding of the processes of risk and resilience, and appropriate related interventions, is limited with respect to other diagnoses, among more diverse families. Similarly, little is known about cultural and ethnic differences in the relationship of parental mental illness and child outcomes (Oyserman et al., 2000).

\section{Pathways of Influence}

In a recent review of the literature on the risk for psychopathology among children of depressed mothers, Goodman and Gotlib (1999) define a model that provides a useful framework for the current discussion. Although their model focuses on "risk" for poor outcomes, i.e., psychopathology, it provides a framework for discussing both risk and resilience among children who have a parent with mental illness.

Based on existing data, Goodman and Gotlib (1999) identify pathways between parent diagnosis of depression and child outcomes that involve multiple mediating and moderating processes. Mediators explain why, or through what mechanisms, parental mental illness is 
related to child outcomes, while moderators influence the quality of the relationship, or to what degree parental mental illness impacts child outcomes (Baron \& Kenny, 1986). Specifically, Goodman and Gotlib (1999) propose that parental depression is related to several "mechanisms of risk" (i.e., mediators) that result from parental depression. These confer vulnerability on the child that ultimately leads to psychopathology. In addition to these mediating factors, the authors list moderating factors that interact with mediating variables to increase risk for child vulnerability and negative outcomes (Goodman \& Gotlib, p. 461). Moderators distinguish between different subgroups of families in which a parent has a mental illness. For example, availability of a father without mental illness in the context of maternal mental illness can enhance child outcomes, such that families with a second parent do better, and single-parent families do worse (Oyserman et al., 2000). Availability moderates the relationship of parental mental illness and child outcomes.

\section{Mediators of the Relationship of Parental Mental Illness and Child Outcomes}

Genetic Influences. Research clearly indicates that certain mental illnesses run in families (Hammen, 1991; Kendler \& Diehl, 1993). This is true whether studies begin with a cohort of adults with psychiatric diagnoses and examine rates of diagnosis among their children; or with a cohort of children with diagnoses and examine rates of mental illness or symptomotology among parents. There may also be specificity for transmission of diagnosis from parents to children. Children of parents with affective disorders are more likely to manifest affective disorders than other disorders, children of parents with an anxiety disorder are more likely to manifest anxiety disorders, and children of parents with both depression and anxiety are more likely to manifest similar comorbidity (Biederman et al., 2001; Warner, Mufson, \& Weissman, 1995; Weissman, 1989).

The strong evidence for increased prevalence of diagnosis within families does not however, "prove" heredity of mental illness. It is difficult to tease out genetic from environmental influences in families where both genes and environment are shared. Risk for diagnosis among children may result from the stressful and disruptive environment potentially created by a parent's illness, a child's illness, or the multiple stressors (e.g., family disruption) that co-occur with psychiatric diagnoses for both adults and children (Silverman, 1989). Thus, research strategies that can distinguish between genetic and environmental influences are necessary to understand the relative role of these two factors. Recent research has begun to employ such strategies.

Twin and adoption studies are generally considered the "gold standard" in genetic research. Both have supported a unique role for heredity in the transmission of mental illness from parent to child. Twin studies have shown that monozygotic twins who share identical genetic structure, show significantly higher concordance rates for schizophrenia (Hanson, Gottesman \& Meehl, 1977), and anxiety (Andrews, Stewart, Allen, \& Henderson, 1990) than dizygotic twins, who share no more genetic similarity than any siblings. Adoption studies further reveal that adopted-away children of parents with schizophrenia (Kendler \& Gardner, 1997; Tienari, Wynne, Moring \& Lahti, 1994) and anti-social personality (Mason \& Frick, 1994) disorder are at greater risk for these or related diagnoses, respectively, than adopted-away children whose parents did not have these diagnoses. However, a large study of adopted children in Finland (Tienari et al.) showed that risk for schizophrenia may result from an interaction between genetic predisposition and difficult adopted-family environment. 
Using a complementary strategy of investigation, Todd et al. (1996) have examined extended families of adults with affective illnesses. They found that risk for diagnosis was greater among first-degree relatives and offspring, compared to second and lesser degree relatives. In addition, they found that bipolar disorder showed stronger heritability than unipolar depression.

Biological Influences. There is growing support that children of parents with mental illness may be constitutionally vulnerable at birth. Infants of mothers with schizophrenia have been found to be at greater risk for fetal and neonatal death, and more vulnerable to negative consequences resulting from obstetrical complications (Walker \& Emory, 1983). Similarly, infants of mothers with depression have shown greater delivery complications, lower Apgar scores, lower tonus and less self-quieting ability (Sameroff, Barocas, \& Seifer, 1978). Psychiatric diagnoses are also associated with biochemical dysregulation (Goodman \& Gotlib, 1999). Recent investigations have supported the possibility that maternal dysregulation or its effects during pregnancy may influence neuroendocrine dysregulation in infants. This dysregulation may be related to emotional and behavioral functioning during infancy and to the development of later emotional and behavioral problems (see Goodman \& Gotlib for review). For example, studies of depressed, pregnant women have found that levels of hormones associated with depression and stress were abnormally elevated during pregnancy (Goodman \& Gotlib; Smith et al., 1990). A single study (Glover, Teixeira, Gitau, \& Fisk, 1998) indicated in addition, that variation of fetal levels of one of these hormones, cortisol, was explained by maternal levels at 20 to 36 weeks of pregnancy. Thus, maternal cortisol levels were related to fetal levels. However, Goodman and Gotlib (1999) caution that the link between exposure to neuroendocrine dysregulation and outcomes needs to be confirmed in additional studies, and the link between immediate outcomes and development of later psychopathology needs further investigation.

In addition to neuroendocrine abnormalities, the presence of mental illness during pregnancy may compromise a mother's health behaviors and prenatal care that, in turn, may result in a less nurturing fetal environment and biological transmission of risk (Goodman \& Gotlib, 1999). It is important to reiterate that the choices of mothers with mental illness about health behaviors during pregnancy are complicated, and may be as strongly related to stigma and fear of loss of custody, as they are to the presence of mental illness (Nicholson, 1996; Nicholson et al., 1998a, 1998b).

Illness Characteristics. The relationship of specific parental diagnoses to child outcomes is unclear. Early studies found no lasting differences on a variety of child outcomes across different diagnoses (Sameroff \& Seifer, 1983). However, newborns of depressed women showed worse outcomes on obstetrical status and neonatal autonomic functioning than newborns of women with schizophrenia, causing speculation that children of depressed mothers may be at greatest risk (Sameroff \& Seifer). By contrast, a more recent study revealed that mothers with schizophrenia showed weaker parenting skills than mothers with affective disorders, suggesting that these children may be at greater risk (Goodman \& Brumley, 1990; Oyserman et al., 2000). Most evidence, however, indicates that severity of symptoms, chronicity of illness, and lower adaptive functioning of parents are more closely related to poor child outcomes than are particular diagnoses (Sameroff et al., 1978; Sameroff \& Seifer; Warner et al., 1995). Other parental illness characteristics that have been found to be predictive of worse outcomes include 
earlier age at onset of parental depression (prior to 30 years old), and comorbidity of depression and anxiety (Warner et al.; Wickramaratne \& Weissman, 1998).

Environmental Influences. Non-genetic and non-biological factors also play important mediating roles in the transmission of risk for and resilience to psychiatric diagnosis (Silverman, 1989). In particular, research has identified important individual and family characteristics that are associated with parental mental illness and child outcomes. Most notably, these include parenting behavior, marital or partner relationship, and family functioning.

Numerous studies suggest that parenting behavior is affected by the presence of mental illness, and that parenting has a strong influence on child outcomes. Research indicates that mothers with mental illness show a range of difficulty with parenting, and that these difficulties may differ somewhat as a function of diagnosis. Mothers with schizophrenia and affective disorder diagnoses both show decreased verbal and emotional responsiveness compared to well parents (Goodman \& Brumley, 1990). Mothers with schizophrenia appear to express less anger and hostility than either well mothers or mothers with depression (Goodman \& Brumley), while mothers with depression have been found to express greater levels of hostility that well mothers (Goodman \& Gotlib, 1999). In addition, mothers with depression exhibit latent, less contingent responses, increased expression of sadness, and irritability, and less expression of positive emotions (Goodman \& Gotlib).

These parenting characteristics in turn, have been shown to be associated with poorer attachment (Radke-Yarrow et al., 1995), and developmental delays in language, attention, and social competence among infants and toddlers (Goodman \& Brumley). Additional work with depressed mothers has indicated that they tend to withdraw from confrontation and conflict with children, rather than engage in negotiation (Kochanska, Kuczynski, Radke-Yarrow \& Welsh, 1987), and that depressed affect in mothers may influence decreased expressions of anger by other family members including children. Such parenting styles may influence the development of maladaptive coping styles and interpersonal skills associated with depression and anxiety in children (Goodman \& Gotlib). More research is needed to support links between specific parenting behaviors and specific child outcomes.

Depressed mothers also show differences in cognitive processing from non-depressed mothers. Parents with depression engage in more negative information processing, and are more likely to have negative attribution styles and to evaluate themselves poorly as mothers (Goodman $\&$ Gotlib, 1999). Studies have shown that children of depressed mothers have similar cognitive styles and negative self-concepts (Garber \& Robinson, 1997; Nolen-Hoeksema, Girgus, \& Seligman, 1992); and that these styles may be somewhat dormant under positive conditions, but can be "turned on" by exposure to situations that raise negative emotions (Taylor \& Ingram, 1999). Thus, depressed parents may be modeling cognitive styles that increase their child's vulnerability to depression.

Unfortunately, there has been no investigation of strengths among parents with mental illness, nor of the potential relationship of these strengths to child outcomes. As noted above, however, parents with a mental illness identify parenting as an important and valued role in their lives, and reflect the same desire as non-ill adults, to be the best parents possible (Mallen, 1999; Mowbray et al., 1995b; Nicholson et al., 1998a).

The quality of a marital or partner relationship has been shown to be a strong mediator of the relationship between parental diagnosis and child outcomes (Goodman \& Gotlib, 1999; Weintraub, 1987). Although research has focused on marital discord as a negative mediator, 
some recent work indicates that supportive partnerships may contribute to resilient outcomes in children (Oyserman et al., 2000). This phenomenon will be discussed further in the following section on moderators. Marital discord and divorce are more common among families in which a parent has a mental illness, and adversely effect both the ill parent and children (Downey \& Coyne, 1990; Fendrich, Warner \& Weissman, 1990; Weintraub). Marital discord predicts a host of child and adolescent problems, including lower academic performance, poor social skills, and conduct problems (Downey \& Coyne; Emery, Weintraub, \& Neale, 1982; Fendrich et al.). Investigations attempting to distinguish between the effect of marital discord and depression have found that discord rather than depression may be the stronger predictor of child problems (Caplan, 1989; Emery et al.). Thus, interventions for couples in which one or both parents are depressed may be particularly beneficial for children.

A chaotic home environment, lower family cohesion, increased parent-child discord, and poorer communication are more prevalent among families with a parent with depression or schizophrenia (Fendrich et al., 1990; Warner et al., 1995; Weintraub, 1987). These features of family functioning are, in turn, associated with increased risk for emotional and behavioral problems in children (Davies \& Windle, 1997; Warner et al.; Weintraub). In a study comparing different levels of family relationships, Dickstein et al. (1998) found that family-level interactions may be more influenced by the presence of parental mental illness than individual parent-child, or spousal relationships. Thus, risk to children may ensue more from family-level interactions not assessed in prior studies of parent-child relationships. By contrast, parent-child relations may be a relative strength for parents with a mental illness, and a promising avenue for intervention.

\section{Moderators of the Relationship between Parent Mental Illness and Child Outcomes}

As described above, moderating variables are factors that do not result from a parent's mental illness, but that can enhance or worsen child outcomes in the context of parental mental illness. Moderators, therefore, may provide particularly fruitful avenues for intervention. As discussed throughout this paper, multiple socio-political factors such as political climate, stigma, and the availability of funding for appropriate programs influence the effects of parental mental illness on children, and the risk for the development of problems among children. Additional moderators of the relationship between parental mental illness and child outcomes include characteristics of the spouse or partner, environmental stressors and supports, child characteristics, and therapeutic intervention.

Spouse or Partner Characteristics. The presence and availability of a supportive spouse or partner has been shown to enhance outcomes for both children and adults in a family in which a parent has a mental illness (Musick, Stott, Spencer, Goldman \& Cohler, 1987; Puckering, 1989; Tannenbaum \& Forehand, 1994; Webster, 1992). In contrast, mental illness and/or substance abuse in the spouse or partner can increase the negative impact of parental mental illness on children both directly, and indirectly, by contributing to increased stress and poorer family functioning (Downey \& Coyne, 1990; Warner et al., 1995).

Environmental Stressors. Chronic and/or acute stressors outside the family can also moderate the impact of parental mental illness on children. More specifically, the stress associated with minority status, low levels of education, single parenthood, social isolation and poverty increases the likelihood of emotional and behavioral problems in children of parents 
with mental illness (Beidel \& Turner, 1997; Hammen et al., 1987; Harnish et al., 1995; Sameroff $\&$ Seifer, 1983). Moreover, in families with a parent with depression where stress was low, support high, and depressive symptoms less severe, significantly fewer children exhibited mental health problems than children from all families with a parent with depression $(10 \% \mathrm{v} .25 \%$; Billings \& Moos, 1983).

Child Characteristics. Initial exploration of the relationship between parental mental illness and child outcomes presumed unidirectional influence, i.e., parental illness affects children. More recent work is revealing that effects may be bidirectional and transactional, with children's characteristics influencing parents' symptoms and behaviors which, in turn, affect children's behavior and functioning (Goodman \& Gotlib, 1999; Hammen, Burge, \& Adrian, 1991). For example, problematic child behavior creates stress for parents that can exacerbate parents' symptoms and/or can elicit poor parenting practices that, in turn, increase child conduct problems (Cox, Puckering, Pound, \& Mills, 1987; Hammen, Burge, \& Stansbury, 1990; Keitner \& Miller, 1990).

Child characteristics such as temperament, intelligence, social skills, and cognitive processes have been shown to be important sources of risk and resilience for children. Greater intelligence, and strong interpersonal skills (Beardslee \& Podorefsky, 1988; Radke-Yarrow \& Sherman, 1990) appear to protect children in both the short and long-term from adverse outcomes. Cognitive characteristics such as a positive and coherent self-concept, a positive attribution-style, and effective coping and problem-solving abilities have been associated with good outcomes among children in general and among children with depressed mothers in particular (Beardslee \& Podorefsky; Downey \& Walker, 1989; Radke-Yarrow et al., 1995)

Child gender also appears to be an important and potentially complex moderating factor in the relationship of parental mental illness and child outcome. Some studies have shown that girls are more adversely affected than boys by a parent's depression (Davies \& Windle, 1997; Hops, 1996), while other studies have shown that boys fare worse (Gross, Conrad, Fogg, Willis, \& Garvey, 1995). Studies also show that girls and boys may show divergent responses, with girls more likely to develop depression, and boys more likely to show conduct problems (Cummings \& Davies, 1994). A recent study further indicated that gender may interact with family functioning such that poor family functioning secondary to maternal depression predicts conduct problems in girls, but not in boys (Davies \& Windle).

The relationship of children's age and exposure to parental mental illness is also unclear. Data indicate that repeated exposure to parental illness and the disruption it can create for children are harmful, events more likely to occur if illness occurs when children are young (Oyserman et al., 2000; Sameroff \& Seifer, 1983). This has been supported by a single study that showed worse behavior problems among younger children of parents with depression (InoffGermain, Nottelmann \& Radke-Yarrow, 1997). However, several studies have failed to find age or developmental effects (Oyserman et al.; Weissman, 1989).

Therapeutic Intervention. An intervention may be targeted to and influence mediating or moderating variables and, therefore, become a moderator in the relationship between parental mental illness and child outcomes. Recent years have seen the development of increasing numbers of programs for parents with mental illness. (See the section on Programs for Parents with Mental Illness and their Families of this paper for a more complete description of programs; Oyserman et al., 1994.) However, little standardized evaluation data exist for these programs 
with respect to child and/or family outcomes. Two intervention projects have provided some promising results.

The Thresholds Mothers' Project in Chicago is a comprehensive services program for mothers with serious mental illness and their young children (aged 0 to 5 years) (Musick et al., 1987). Mothers receive mental health services, parenting education and support. Children and parents attend a therapeutic nursery staffed by child development specialists who work with the children and "coach" the mothers in child development and appropriate play. A five-year study of The Thresholds Mothers Project (Musick et al.) indicated that both mothers and children showed improvement over time. Children evidenced increases in Developmental Intelligence, Intelligence Quotient, social competence and adaptive skills. Mothers' showed enhanced attentional skills, social adjustment, and adjustment to work and parenting roles (Musick et al.). No significant differences in child or maternal outcomes were noted for a comparison of Thresholds' participants and participants in a much less comprehensive home-based aftercare program where participants received weekly visits from a psychiatric nurse or social worker (Musick et al.).

In a second intervention program for families coping with parental affective illness, Beardslee and colleagues provided education to parents and children about the parents' illness and the potential effects of parental mental illness on the family. Results showed that families reported improvements across many areas of behavior and attitude consistent with better child outcomes (Beardslee et al. 1997a, 1997c; Beardslee, Wright, Rothberg, Salt, \& Versage, 1996b). These changes included improved family and parent-child communication, increased communication between parents and children about depression, and adoption of new family/parenting coping strategies, among others. Children reported better understanding of parental illness, and better adaptive functioning, however some of the children experienced significant symptoms in the period of observation after the intervention (Beardslee et al., 1997c).

SUMMARY: Research on child outcomes has uncovered multiple sources of risk and resilience for children who have parents with mental illness. The majority of studies have focused on white, middle class samples of children of depressed mothers. It is therefore difficult to know whether these same models might be applied more generally across race, class and parental psychiatric diagnoses. In addition, the influence of ethnic and cultural differences is not understood. Within these limitations, studies have revealed that both genetic/biological and environmental factors can be sources of risk and resilience. However, most investigations of resilience have focused on environmental variables. Specifically, studies have revealed that heredity, severity and chronicity of illness, parenting behavior, marital discord, and family relationships are important mediators of the relationship of parental mental illness and child outcomes. Spousal or partner characteristics, environmental stress and support, and child characteristics such as temperament, cognitive styles and interpersonal skills are important moderators. Studies have focused heavily upon sources of risk, and may have missed potentially powerful sources of resilience upon which interventions might be based. Data do not reflect children's subjective experience of parental mental illness, or reports of what children think might be useful. In spite of these limitations, interventions founded upon what is known about sources of risk and resilience have been somewhat fruitful, though few and far between. In particular, efforts to enhance children's understanding of mental illness and parents' understanding of children's needs have shown promising results. 
RECOMMENDATIONS: Increased research attention must be paid to strengths and sources of resilience among both parents and children; and to how sources of both risk and resilience relate to ethic and cultural differences. Children must be asked about their experiences of living with parents with mental illness, and their needs. Effort should be made to bridge the gap between research and practice. Current knowledge about sources of risk and resilience should be translated into practical interventions that enhance sources of resilience and mitigate sources of risk. These interventions should be evaluated for effectiveness. 


\section{Chapter V}

\section{Policies, Practices, and Parents with Mental Illness}

CRITICAL ISSUE: A number of federal policies and state practices have potential ramifications for parents with mental illness and their families. The consequences of these policies and practices for families in which parents have mental illness are largely unstudied.

Several key issues are described below, based on review of available written materials and the comments of key informants. Key informants are researchers, consumers, policymakers, and service providers who work in fields related to parenting and mental illness. The review is supplemented by research findings where they exist.

\section{Adoption and Safe Families Act}

The federal Adoption and Safe Families Act, Public Law 105-89 (ASFA) was signed into law on November 19, 1997. This legislation was passed by Congress with bi-partisan support and is the first substantive change in federal child welfare law since the Adoption Assistance and Child Welfare Act of 1980, Public Law 96-272.

ASFA is intended to address the issue of foster-care drift and to achieve a balance of safety, well-being and permanency for children in foster care. ASFA requires that state child welfare agencies make "reasonable efforts" to prevent the unnecessary placement of children in foster care and to provide services necessary to reunify children in foster care with their families. In certain circumstances, ASFA allows for the "reasonable efforts" statute to be bypassed, when it would not be reasonable to reunify children with their parents. ${ }^{1}$

The intention of ASFA is to promote safety and permanency for children who are alleged or determined to be abused and neglected, and to ensure that children do not languish in out-ofhome placements, but are moved swiftly to either reunite with a parent or move to a permanent alternative living situation. ASFA seeks to promote permanency by establishing expedited timelines for determining whether children who enter foster care can be moved into permanent homes promptly--their own familial home, a relative's home, adoptive home, or other planned permanent living arrangement.

Two new timelines are imposed. First, permanency hearings must be held for children no later than 12 months after they enter foster care (six months earlier than the prior Child Welfare Act of 1980). Second, state child welfare agencies must review existing caseloads and track new children entering into care so that termination of parental rights (TPR) proceedings will be initiated for children who have been under the responsibility of the state for 15 out of the most recent 22 months (Rauber \& Granik, 2000). Once the TPR petition is filed and the proceedings are initiated, a court must determine first whether there are grounds for termination of the parents' rights and, second, whether it would be in the child's best interest to do so. (Children's Defense Fund, 2000). (Eventually both parents' rights must be terminated for a child to be free for adoption.) "Fifteen of the last 22 months" is a maximum timeframe; the state has discretion to file a TPR petition whenever it sees fit in the best interest of the child (Baker, 2000).

\footnotetext{
1 "Reasonable efforts" to provide services for the family may be bypassed if: The child has been subject to aggravated circumstances (as defined by state law) by the parent; The parent has been convicted of certain crimes; and, The parent has had involuntarily termination of rights to another child.
} 
ASFA includes three circumstances that can preclude filing a TPR petition, even if the child has been in care for 15 out of 22 months: (1) the child is in the care of a relative; (2) the state agency documents a compelling reason why filing is not in the best interest of the child; or (3) the state agency has not provided to the child's family the services deemed necessary to return the child to a safe home consistent with the time period in the case plan. All fifty states and the District of Columbia have passed legislation to address the mandates required by ASFA. Receipt of federal child welfare funding was contingent upon the adoption of ASFA by state governments.

While the intent of ASFA is to protect the health and safety of children, the implementation of the law also seems, in many instances, to be detrimental to the interests of parents with mental illness. An attorney interviewed as a key informant indicated that in many cases, ASFA makes reuniting families where a parent has a mental illness more difficult. While family and environmental stability clearly contribute to positive outcomes for children, severing ties with birth parents also has costs (Miller, 1997; Nicholson, 1996). It is not always clear that these costs are outweighed by the benefits of foster care placement or adoption, or that terminating these relationships is always in the child's best interest.

Key informants working in this area noted that the chronic nature of mental illness combined with the limited number of specialized programs targeted to work with these families may make it more difficult for parents to regain custody of children before the 15 month window has passed. Fifteen months is an extremely narrow time frame when you factor in the often uneven course of mental illness and recovery, and the time needed for comprehensive family evaluation, treatment planning and adequate participation in services. Our research suggests that relatively few programs exist specifically to assist parents with mental illness and their families. Thus, the attempts of child welfare agencies to provide "reasonable efforts" to prevent removal of children or promote reunification of families may be difficult, if not impossible.

Key informants recommended that if a child is removed from a parent's custody, appropriate services must begin as soon as possible to avoid unnecessarily lengthy periods of separation between parent and child. All parties involved with the parent and family, i.e. lawyers, caseworkers, therapists, must work towards the common goal of finding and accessing services. If a parent is currently unable to care for his or her child, key informants advise that relatives be used as placement resources whenever possible, as this provides an exception to the requirement that a TPR be filed after 15 months of foster care placement. However, this may be contraindicated in situations in which relatives themselves have been abusive as parents, or are purposely seeking to undermine their family member's capacity to parent (Nicholson et al., 1998b).

SUMMARY: ASFA may have unintended consequences in its implementation. The incentives for permanency planning may motivate child welfare agencies to focus on out-ofhome placement and planning for children in the allotted time frame, rather than to tackle the oftentimes complex needs of parents with mental illness. Fifteen months may not be enough time for thorough family evaluation, comprehensive planning, service implementation, and necessary progress to be documented. Compounding this, it appears that state child welfare agencies may often be unable to comply with "reasonable efforts" to prevent placement, or to promote reunification when services for families where a parent has a mental illness are limited. Child welfare staff, law enforcement personnel, attorneys, guardians ad litem, and the judicial system 
may be subject to the same misunderstandings and lack of knowledge about mental illness as the general public.

RECOMMENDATIONS: Given the emphasis on the developmental needs and wellbeing of children implied by the ASFA 15-month time frame, care must be taken to provide effective services to all family members immediately. Children's best interests, and parents' needs may be met by comprehensive, specialized, in-home services, so that separations are not necessary or so they can be minimized. The oftentimes-chronic nature of parental illness and uneven course of recovery require interventions to be both flexible and individualized to meet the unique needs of families. Efforts to find and access services for families must be coordinated and integrated at all levels of care and across systems of care. Child welfare and mental health policymakers and administrators must provide and coordinate resources to support the crosssystem needs of children and their parents who have mental illness. The relationship between mental health and child welfare is a focus of the Substance Abuse and Mental Health Services Administration (SAMHSA) Child Health Service Act of 2000, underscoring the necessity of understanding and enhancing relationships between the two systems on behalf of children and families living with mental illness.

Training is a critical component for all of areas of the service system. Better education regarding mental illness, the relationship of mental illness to parental competence, safety and risk issues for children who have a parent with mental illness, and the impact of the termination of parental rights on children and adults are training areas that need to be provided for within the judicial system, the child welfare system, and the mental health system. Ultimately the costs of severing family ties must be empirically documented and weighed against the benefits of out-ofhome placement and permanency planning on a case-by-case basis for families in which parents have mental illness. Research is needed to evaluate the costs and benefits of one choice over the other.

\section{Americans with Disabilities Act}

At first glance, the Americans with Disabilities Act (ADA) appears to present an ideal opportunity to advocate for and secure appropriate services for adults with mental illness who are parents. According to Title II of the ADA, state and local governments must provide people with disabilities equal opportunity to benefits from all programs, services and activities, e.g., public education, employment, transportation, recreation, health care, social services, courts, voting, and town meetings. State and local governments are required to make reasonable modifications to policies, practices and procedures where necessary to avoid discrimination, unless it is demonstrated that doing so would fundamentally alter the nature of the program, service, or activity being provided. Because child welfare agencies are covered under Title II, these programs, benefits, and services cannot discriminate on the basis of disability. Accommodations in services are required for those individuals whose needs are not met by existing services.

In December, 1999, the United States Supreme Court issued its decision in the case of Olmstead v. L.C. (527 U.S. 581, 144 L.Ed 2d 540, 119 S.Ct. 2176). The Court found that the ADA prohibits discrimination in the provision of public services and that no qualified individual with a disability shall, "by reason of such disability," be excluded from participation in, or be denied the benefits of, a public entity's services, programs, or activities. The Court further noted that in regulations issued by the Attorney General, pursuant to the authority of the ADA, a "public entity [is required to] administer... programs...in the most integrated setting appropriate 
to the needs of qualified individuals with disabilities (See 28 CFR $\S 35.130[\mathrm{~d}]$ ). The Court also found that while public entities are not required to "fundamentally alter" the nature of their programs, they are required to make "reasonable modifications to avoid "discrimination on the basis of disability." (See 28 CFR § 35.130[b] [7]).

However, the ADA has provided little direct protection to parents with mental illness. Key informants working at the interface of mental health and the law note that numerous state courts have heard challenges to the ADA regarding the process of terminating parental rights of adults with mental illness. A number of state and federal courts have entertained ADA cases arguing the lack of reasonable accommodations for parents with mental illness (A. Grudzinskas, personal communication, January 18, 2001; Kerr, 2000; Mosier, 1998). In individual termination of parental rights hearings, several courts have argued that the rights of parents to services or accommodations in services are not included in the "benefits, services or programs" indicated by Title II of the ADA (Stefan, 2000). With the exception of a lower court ruling in Texas, no state has successfully called on the ADA to challenge parental rights terminations.

One legal expert key informant noted that parents may be discouraged from bringing ADA cases specific to parenting with a mental illness, seeing them as, "an ineffective use of time, money and resources." Some advocates, however, have had success arguing for state mandated parental supports in cases where a parent has a developmental disability. In many cases, the ADA has been inappropriately applied where the facts did not warrant a discrimination claim, for example, in situations in which the termination of parental rights was appropriate on grounds having nothing to do with a person's mental illness. In some states, Massachusetts for example, existing case law prohibits discrimination in termination of parental rights cases based solely on the question of someone's mental illness. The ADA defense is therefore not utilized since its use would require developing a new body of law.

The ADA affords less protection to parents with mental illness in cases of child custody, even though child welfare agencies and state statutes were intended by Congress to be subject to the ADA. (The recent U.S. Supreme Court decision in Board of Trustees of the University of Alabama v. Garrett, 121 S.Ct. 955, 148 L.Ed 2d 866, which held that Congress exceeded its authority in abrogating the State's Eleventh Amendment immunity from suits, applies on its facts, only to money damage actions against the States in employment suits, and does not affect the actions discussed in this paper.) Decisions of state court judges regarding custody cases between competing parents most likely cannot be challenged under the ADA (Stefan, 1998).

SUMMARY: To date, the ADA has afforded little protection to parents with mental illness in termination of parental rights situations.

RECOMMENDATIONS: The ADA remains a potentially useful approach to defending against the termination of parental rights when properly applied in appropriate cases. Key informants recommended that advocates from all disciplines should coordinate efforts to make parenting with a disability a defendable right under the ADA. Lawyers, consumers, family members, providers and policy-makers could learn from other disability rights activists, e.g., developmental disability advocates, who have successfully defended the rights of parents, and incorporate these techniques into current advocacy efforts. 


\section{Personal Responsibility and Work Opportunity Reconciliation Act}

The latest effort in welfare reform, the Personal Responsibility and Work Opportunity Reconciliation Act (PRWORA), has a potentially mixed impact on parents with mental illness. Low-income families, particularly women receiving welfare, have disproportionate rates of serious mental illness (Moore, Zaslow, Coiro, Miller \& Magenheim, 1996). The five-year lifetime limit on assistance and the requirement that recipients obtain jobs after two years of continuous support are of particular concern given the prevalence of depression in women on welfare, and the relationship between depression and employment (Lennon, Blome, \& English, 2001). New work requirements, detailed in the Temporary Assistance to Needy Families (TANF) state block grants, do not specifically consider mental illness as a barrier to work (Knitzer, 2000). While states have some flexibility when working with high-risk recipients, no requirements exist to explicitly protect the interests of persons with mental illness.

Mothers with mental illness in the welfare system are at a distinct disadvantage. Low paying work and the lack of job training programs for persons with mental illness are common obstacles to employment. Employers may be unwilling to hire persons with mental illness because of the stigma attached, often regardless of a person's ability to do the work required. Individuals with mental illness may need long-term support with all aspects of employment, including career planning, job negotiations, and learning new skills (Bond, Drake, Becker \& Mueser, 1999). Finding and affording childcare are major stressors for all mothers, and are additional stressors for women juggling the multiple demands of parenthood and living with mental illness.

Welfare reform advocates report a linkage between depression and employment, and economic barriers for women, a finding supported by the research literature (Lennon et al., 2001; Moore et al., 1996). Key informants also reported that few mothers and families on welfare receive mental health treatment, and families remaining on the welfare rolls since PRWORA are often the most vulnerable.

SUMMARY: There are high rates of mothers with mental illness on welfare with no supports. Without appropriate supports, mothers with mental illness may be unable to comply with PRWORA/TANF regulations, resulting in greater compromise for families as they are unable to access benefits. PRWORA and TANF do not consider how the stressors of mental illness and work interact with the work of being a parent.

RECOMMENDATIONS: The unique circumstances of mothers with mental illness in the welfare system must be acknowledged. Resources must be in place to provide supports to mothers with mental illness on welfare and their families. Recent legislation, such as the Ticket to Work and Work Incentives Improvement Act, supports persons with disabilities moving towards work and independence. Job training addressing issues of work and mental illness could benefit both potential employees and employers. Accessible and affordable child care are essential to all families with working parents, and are extremely important to parents with mental illness, given their worries and concerns about their children's well-being.

\section{Managed Care and Mental Health Carve-Outs}

There are no data on the needs or service utilization issues of parents with mental illness in the private sector, particularly in the current managed care environment. It is not known 
whether the protocols for decision-making by managed care organization (MCO) gatekeepers or utilization review staff are sensitive to the needs of adults with mental illness who are parents. We are aware of a recent case in which, in order for reimbursement for a new mother's psychotherapy for depression to be authorized by her MCO, she was required to take antidepressant medication. Because of this, she was unable to continue breast-feeding ("Taking a Different Path," 2000). Standard treatment protocols used by MCOs in decision making may be vulnerable to the same stigma and assumptions at work in the public sector, i.e., that adults with mental illness are not recognized as parents.

Managed care organizations (MCOs) have the opportunity to develop initiatives, authorize preventive services, and coordinate providers' efforts, which could reduce mental health service costs both for parents and children over time. The primary care venue may provide opportunity for the early identification of problems and intervention for both parent and child, assuming assessment and treatment issues can be effectively addressed (U.S. Department of Health and Human Services, 2000a). The emphasis of MCOs on wellness and prevention is complementary to the notion of parenting interventions, both as adjunct to treatment for adults with particular mental health issues, as well as supporting resilience in children. MCOs might well avoid later costs associated with mental health services for children through earlier preventive efforts with those deemed to be "at risk" (Beardslee et al., 1997a, 1997c). Employers who are concerned about worker productivity and days on the job could encourage MCOs to support adults with mental illness in dealing with parenting and their children's issues. While parenting supports seem to fit with the philosophy of managed care, services specifically for parents such as support groups or psychoeducation interventions are not traditionally third-party reimbursable.

As state mental health agencies (SMHAs) move towards managed care initiatives to coordinate their public mental health effort, it is important to consider how the "privatized," "carved-out" public sector mental health system responds to adult clients who are parents. The number of states with public sector managed behavioral health programs has tripled over three years. In 1999, 42 states had some form of managed behavioral health care, compared to 1996 when 14 states had managed care programs (U.S. Department of Health and Human Services, $2000 \mathrm{~b}$ ). By providing public sector mental health services through managed care organizations, SMHAs are delegating assessment and treatment functions to private companies, thereby, in some sense, both abdicating responsibility and missing opportunities to influence standards of care and practice. Several SMHAs in our survey could not tell us whether their public sector clients were parents simply because they assigned the responsibility for background data collection to the MCO.

SUMMARY: Managed care organizations may overlook the unique needs of their adult subscribers with mental illness who are parents in their standardized treatment authorization and utilization review processes. In not considering the interaction of parental mental illness, treatment recommendations, families' needs, and increased health care expenditures, MCOs may be missing opportunities to coordinate and deliver preventative and palliative care to minimize ultimate costs for adults and children. The typical MCO short-term view of the healthier slice of the population mitigates against enhanced long-term outcomes or cost savings. By providing public mental health services through private, managed care organizations, SMHAs may be missing opportunities to influence standards of care. 
RECOMMENDATIONS: Given the prevalence of women and men with mental illness who are parents, it is in the employers' best interest to review standards and policies in light of the needs of families, and begin working towards wellness for both adults and children. Parenting interventions are complementary to a coordinated, family-centered preventative approach, promoting positive, pro-active health care for both adults and children. MCOs have the opportunity to reach families through mental health and primary care venues before children develop problems. It is in the best interest of states, which benefit from long-term planning and prevention, to contract with MCOs for services that include a focus on prevention and palliative care.

\section{State Mental Health Agencies}

In 1999, 51 SMHAs were surveyed (including the District of Columbia) to explore whether and how public sector mental health systems respond to the needs of adult clients who are parents. Results indicate fewer than 25 percent of SMHAs formally identify adult clients as parents (Nicholson, Biebel, Hinden, Henry \& Stier, unpublished raw data). Ten years previous, a similar survey found only 31 percent of SMHAs routinely collected data on whether women had preschool-age children (Nicholson et al., 1993). Results suggest SMHAs' attention to the needs of clients as parents has become increasingly limited over the last decade. This decrease in attention is also seen with regards to assessing parent functioning. In 1999, approximately 20 percent of SMHAs assessed adult clients' functioning as parents, while 1990 survey results indicate 45 percent of SMHAs provided opportunities for assessment of parents' skills.

The 1999 survey also explored coordination between SMHAs and other state systems regarding families in which parents have mental illness. Results suggest SMHAs are most likely to coordinate with the child welfare or education/early intervention systems, and least likely to coordinate with the corrections system. Coordination with SMHAs most often occurs through interagency collaborations or multi-agency team meetings. Few SMHAs coordinate efforts with other systems through linked information systems or uniform service application or intake forms.

Results from the 1999 SMHA survey support the traditional notion of SMHAs serving only eligible individual clients. This is problematic because adults, especially adults with children, live in families around which treatment and services should be designed and implemented. For example, mental health key informants spoke of parent's and children's devastation when hospitals prohibit visitation. The inability of parents and children to be together during these stressful times can be confusing and hurtful. Parents are unable to concentrate on recovery, and children do not understand where their parents are or why they cannot see them. Key informants from the mental health policy arena support the importance of SMHAs' identification of clients as parents, a critical first step to answering the questions, "Who are parents with mental illness?" and "What are their needs?"

SUMMARY: Most SMHAs are unaware of the parenting status of their adult clients. If anything, SMHAs are less responsive to parents in the public mental health system than they were ten years ago, specifically with regards to the identification of parental status and assessment of parenting skills. Systems and services that ignore the needs of individuals as family members, e.g., that pass up opportunities for crisis planning through advance directives, will be less effective in meeting the needs of parents or children. SMHAs unresponsive to the needs of parents and children miss a prime opportunity to work towards recovery and wellness 
for families in the public sector, and may actually contribute to poor outcomes for both the adults and the children they serve.

RECOMMENDATIONS: SMHAs must prioritize both identifying the needs of adult clients as parents, and creating programs and policies that address the issues of clients with children. SMHAs need to embrace the notion of adults with mental illness as parents, both to combat stigma surrounding individuals' abilities to parent, as well as to provide for the needs of families. The individual client model is inappropriate for adults with children, who have a myriad of needs outside of the traditional model of "adult" mental health care. Pro-active, integrated intervention with a family-centered focus must become the standard model of care for mental health services in the public sector. 


\section{Chapter VI}

\section{What Can We Learn From Other Systems and Fields?}

CRITICAL ISSUE: The families of parents with mental illness, and the families of children with serious emotional disturbance have overlapping risk factors and service needs (Katz-Leavy, Nicholson, Banks, Hinden \& Lambert, 2001 presentation). The needs of adults and children living with parental mental illness have been traditionally met by services and providers in several systems. Knowledge about psychiatric disorder in adults, serious emotional disturbance in children and adolescents, and the issues of families living with mental illness must be shared with relevant systems, services and providers. Likewise, efforts to meet the needs of individuals and families originating in arenas other than mental health, can inform efforts in the mental health services arena.

The current "state of the science" in these related fields of study was determined through both an extensive review of the literature and interviews with over thirty key informants. The resultant body of knowledge highlights both critical issues in the field and recommendations for action.

\section{Child Welfare}

Parenting services are often considered to fall under the purview of the child welfare system (Nicholson et al., 1993). The assumption that all parents with mental illness abuse their children is powerful and dangerous. Research investigating the link between parental mental illness and child abuse seems to most frequently implicate personality disorders (especially antisocial personality disorder) and major depression as risk factors for child abuse (Bland \& Orn, 1986; Chaffin, Kelleher, \& Hollenberg, 1996; Dinwiddie \& Bucholz, 1993; Famularo, Kinscherff, \& Fenton, 1992a, 1992b; Taylor et al., 1991). However, alcohol and/or substance abuse have also shown strong associations with child abuse (Chaffin et al.; Dinwiddie \& Bucholz; Famularo et al.), especially when occurring comorbidly with serious mental illness (Bland \& Orn).

There are a number of environmental stressors that often accompany serious mental illness that may increase the risk that parents with mental illness will abuse their children. Researchers have reported that mothers with serious mental illness are likely to be living in poverty (Zemencuk et al., 1995). They often have marital difficulties, and are likely to be divorced or never married (Downey \& Coyne, 1990; Mowbray, Oyserman \& Ross, 1995a). Many have conflicts with extended family and are isolated from social supports (Cox et al., 1987; Nicholson et al., 1998b).

There are also factors that appear to mitigate the risk of child abuse for parents with mental illness. A recent study (Mullick, Miller, \& Jacobsen, 2000) found that the level of insight a mother has into her mental illness is significantly negatively correlated to her risk of abusing her children. Insight into mental illness was also significantly positively correlated with ratings of maternal sensitivity.

Research on the relationship between parental mental illness and child abuse is limited in several ways. Most studies are based on samples of parents who have been determined through the child welfare system or the courts to be abusive, or who report themselves to be abusive. The goal of these studies is to describe profiles of child abusers, or to identify risk factors contributing to an increased likelihood that abuse will occur (Bland \& Orn, 1986; Chaffin et al., 
1996; Dinwiddie \& Bucholz, 1993; Famularo et al., 1992a, 1992b; Taylor et al., 1991). These studies do not actually tell us what percent of parents with mental illness abuse their children, but rather tell us what percent of parents who abuse their children have mental illness. There is no way to know what proportion of the total population of parents with mental illness these parents represent.

SUMMARY: While the prevalence of certain types of mental illness, e.g., antisocial personality disorder or depression, particularly when co-occurring with substance abuse, in samples of known child abusers is higher than what might be expected in the general population, these data do not tell us about the prevalence of child abuse in the families of parents with mental illness. We know more about the likelihood that parents who are child abusers will have mental illness than we know about the likelihood that parents with mental illness will abuse their children. Serious mental illness often occurs together with many environmental stressors that increase the risk of abuse to children, suggesting complex sets of relationships among multiple contributing factors.

RECOMMENDATIONS: Research is required to investigate the likelihood of abuse and neglect in families in which parents have mental illness, and to fully understand the relationship between mental illness and child abuse, in the context of a constellation of factors contributing to risk for children and families. Fortunately these factors may suggest many avenues for intervention.

\section{Early Intervention/Head Start}

Federal legislation mandates family-centered Early Intervention (EI) services for infants and toddlers (ages zero to three) with established diagnoses or demonstrated developmental delay. Some states serve infants and toddlers at-risk for developmental delay as well (Shonkoff \& Meisel, 1991). Risk factors can be both physical, such as low birthweight or exposure to infectious diseases, or contextual, such as living in poverty or having a parent compromised by illness.

The prevalence of parental mental illness in families receiving Early Intervention services is unknown, but anecdotal reports from EI providers suggest a substantial subgroup. Research indicates that children with a parent with a mental illness are at risk for development of emotional or behavioral difficulties; providers of early intervention services have noted the potential deleterious effect of parental depression on children's early development (Goodman \& Gotlib, 1999; Osyerman et al., 2000). Research has shown EI to have moderate positive effects in children, particularly in cognitive and language outcomes (Shonkoff \& Hauser-Cram, 1987). In addition, EI programs focusing on parental participation appear to be more effective than those minimizing or disregarding the role of parents (Shonkoff, Hauser-Cram, Wyngaarden Krauss \& Upshur, 1988).

Started over 30 years ago, Head Start exemplifies the EI philosophy by incorporating the "whole child" perspective of family-centered interventions, working towards wellness for all family members in at-risk situations. Head Start promotes good physical, cognitive and social health, proper motivation, and a parent's ability to participate in his or her child's learning to foster positive outcomes for children entering school (Zigler, 1998). Included in the Head Start philosophy is the belief that a child's community, including family, school and supports, must be part of the path to wellness. 
Head Start's target population - children and families in poverty - is similar in many ways to families in which a parent has a serious mental illness. Both groups are parenting in compromised circumstances that often include low income, unsafe housing, un- or underemployment, and inadequate social networks. While the prevalence of mental illness among Head Start parents is unknown, one administrator of a Head Start program estimated that a third of the families she sees have a parent with depression.

SUMMARY: Children in families in which a parent has mental illness are likely to be at developmental risk, and are likely to be a significant sub-set of the larger Early Intervention population of families. Early Intervention or Head Start efforts have not systematically assessed or focused upon the needs of the possibly substantial subgroup of families in which children are living with parents with mental illness.

RECOMMENDATIONS: Early Intervention programs are an appropriate service option for at-risk children in families where a parent has a mental illness. Advocacy efforts are needed to ensure that families are considered for these services. EI service providers need education about the challenges faced by parents with mental illness, including those related to mental illness itself, as well as issues such as stigma and poverty, that may be barriers to full participation in services.

\section{Substance Abusing Pregnant Women and Mothers}

A significant percent of adults who abuse substances also have co-occurring mental health issues, and rates for comorbid substance abuse among adults with mental illness are high (Kessler et al., 1997). Primary diagnoses include major depression, panic disorder and posttraumatic stress disorder (Helzer \& Pryzbeck, 1994). Women who abuse substances are also at increased risk for attempting suicide (Evans \& Lacey, 1992). There is likely to be considerable overlap between mothers who abuse substances and those with mental illness.

Similar to women with mental illness, substance-abusing women often face a myriad of social, emotional, psychological, and physical problems, in addition to pragmatic concerns about housing, employment, transportation and finances (Alexander, 1996; Finkelstein, 1994; Reed \& Mowbray, 1999). Pregnant and parenting women have a special set of circumstances to consider. Substance abusing pregnant women are at increased risk of contracting sexually transmitted diseases, HIV and Hepatitis B (Alexander; Finkelstein, 1993). Possible outcomes for children include prematurity, low birth weight, Fetal Alcohol Syndrome and HIV exposure, all of which have short- and long-term consequences (See for example Kliegman, Maduna, Diwi \& Eisenberg, 1994; Sonderegger, 1992). Children whose parents abuse drugs and alcohol are more likely to be abused and neglected that children whose parents do not (National Center on Addiction and Substance Abuse, 1999). Substance abusing pregnant women and mothers are less likely to seek prenatal or general health care, due to stigma, denial, the lack of genderspecific treatment options, and the dearth of treatment options for mothers with their children (Finkelstein, 1994; Reed \& Mowbray). In addition, many substance abuse programs will not enroll pregnant and parenting women.

Substance abuse treatment strategies were originally designed for male substance abusers. This trend changed in the mid-1970s, with the passage of Public Law 94-371 mandating the creation of specialized treatment programs for women (Finkelstein et al., 1997). As a result, research and programming specific to substance abusing women has increased over 
the past 25 years. Tailoring programs to women has meant moving away from traditional male dominated, confrontational models of treatment towards modalities that address the different needs of women (Brown, Sanchez, Zweben \& Aly, 1996). The paradigm is shifting from treatment of an individual client, to a mother-child/family-centered orientation in which treatment is coordinated around the family unit, and where prevention and early intervention are stressed. Variations in services may include programs where mothers and children live together in a treatment setting, are educated regarding child development, and where treatment schedules are modified to meet the needs of mothers with small children.

Substance abuse prevention efforts have targeted youth as a vulnerable at-risk population for substance abuse. SAMHSA's Center for Substance Abuse Prevention has identified effective, model programs created to assist youth in overcoming exposure to risk factors through the enhancement of protective factors. (See SAMHSA's web page: www.samhsa.gov/centers/ csap/modelprograms.) Programs like The Strengthening Families Program coordinated by the University of Utah's Health Promotion and Education Department provide interventions including parent training, social and life skills training, and family practice sessions. SAMHSA is creating opportunities for the application and evaluation of these types of intervention strategies to families living with mental illness. For example, the SAMHSA-funded Women with Co-Occurring Disorders and Histories of Violence multi-site initiative will provide empirical evidence of the effectiveness of interventions for families derived from the substance abuse prevention and treatment arena, and applied to the special population of women coping with mental illness, substance abuse, and trauma, and their children.

SUMMARY: There is considerable overlap between the population of parents with substance abuse and those with mental illness, given the high rates of co-occurring substance abuse and mental health disorders and the prevalence of parenting in both groups. However, knowledge gained in the substance abuse treatment community regarding mother-child/familycentered prevention and treatment does not seem to have been applied widely in the mental health arena, though SAMHSA is providing opportunities for the application and evaluation of intervention strategies derived from this arena to other special population, e.g., women with cooccurring disorders and histories of violence, and their children. Few programs have been developed specifically to meet the needs of parents with co-occurring disorders and their families.

RECOMMENDATIONS: Substance abuse and mental health systems and providers need to coordinate and integrate services, and work together with other systems of care (i.e., child welfare, rehabilitation) to create a continuum of care for parents and families. Substance abuse treatment programs that have been modified to meet the needs of women, and to coordinate and provide services for families can serve as models to program development efforts for parents with mental illness and their families.

\section{Women and Trauma/Violence}

Twenty to thirty percent of women in the United States have experienced some form of sexual or physical abuse during their lifetime (Mowbray, Oyserman, Saunders \& Rueda-Riedle, 1998). Abuse is usually not an episodic occurrence, but rather part of a history of violence and trauma. Violence against women is a growing public health crisis (Alexander \& Muenzenmaier, 1998). Victims of violence often struggle with related issues including poverty, homelessness, 
substance abuse and mental illness. Women victims of violence are at increased risk for depression, post-traumatic stress disorder and suicide attempts (Bassuk, Melick \& Browne, 1998; Miller \& Finnerty, 1996). Children are affected by witnessing violence in their home or neighborhood environments (Osofsky, 1995; Overstreet \& Braun, 2000; Schwab-Stone et al., 1995). Having childhood experiences of trauma or abuse can contribute to women's difficulties in current relationships and parenting (Melnick, 1999; Nicholson, 1998 presentation).

Women receiving mental health care are rarely asked about a history of sexual or physical abuse (Levin \& Blanch, 1998). When professionals ignore these experiences, women may discount the devastating impact of violence on their lives. They may not receive needed treatment with respect to trauma or the impact of trauma on parenting. Women with a history of trauma have multiple service needs that are best met through integrated and coordinated systems of care, and a holistic approach to treatment that embraces the related issues of mental health and substance use. Recovery can only be achieved through attention to the interconnectedness of the issues that face women, and through the creation of a multidisciplinary, comprehensive treatment model including, for women with children, the issues of family

SUMMARY: Prevalence of trauma among women and parents with mental illness is likely to be high. Trauma histories are likely to impact overall functioning and parenting in particular. Mental health providers do not always assess trauma histories sufficiently, consider the impact of trauma on parenting, or provide appropriate treatment. The issues of parents who are trauma survivors are disregarded by providers in service planning for adults and in treatment relationships with their children.

RECOMMENDATIONS: Epidemiological studies are needed to describe the extent to which women trauma survivors are parents and, likewise, the extent to which parents are trauma survivors. Descriptive studies are needed to explore the ways in which trauma experiences are related to aspects of parenting among adults with mental illness. Mental health providers need to be aware of the impact of trauma in women's lives, and the need to address this in traumasensitive treatment approaches, particularly with respect to the parenting role. Children's service providers must be sensitive to the needs and respectful of the preferences of all parents and, in particular, the unique issues of those who are trauma survivors.

\section{HIV/AIDS}

Women are the fastest growing cohort for HIV infection in the United States, accounting for $23 \%$ of adult cases from July 1998 to June 1999 (Centers for Disease Control, 1999). As a result, AIDS is one of the leading causes of death in 25 to 44 year old women (Centers for Disease Control, 2000). Women living with serious mental illness are at increased risk for HIV infection, with seroprevalence rates from $4 \%$ to $23 \%$, exceeding the infection rates of the general population (Carey, Weinhardt \& Carey, 1995). This increased risk results from a constellation of factors that may include limited access to health care, poverty, limited educational opportunities, poor living conditions (often in high crime areas), exposure to physical and sexual abuse, and possible cognitive or emotional limitations that may compromise an individual's ability to understand and observe safe sex practices (Aruffo, Coverdale, Chacko \& Dworkin, 1990; Weinhardt, Carey \& Carey, 1998).

While the number of women affected by HIV/AIDS is large, there is little research, policy or programming devoted to the concerns faced by HIV-infected women who are parents. 
Research on drug treatment effectiveness has centered on men while policies towards pregnant women with AIDS stress prevention and often encourage women not to get pregnant. Treatment has primarily focused on the health of the fetus and not the mother (Corea, 1992).

Research has shown it is crucial to address multiple needs when targeting high-risk populations to reduce HIV/AIDS risk behaviors (Kalichman, Adair, Somlai \& Weir, 1995). For pregnant and parenting women, this most often includes their children. Just as mental illness is not the central theme for many parenting women, neither is AIDS/HIV infection. These illnesses are part of the larger challenges many women face, like compromised health, economic circumstances, and social supports, while at the same time trying to parent their children as best they can. While women describe their children as the focal point of their lives, most HIV/AIDS programs provide few services, e.g., family-centered care management, that would overcome parenting-related to obstacles to appropriate and regular medical care (Williams, 1990). Common themes revealed through interviews with HIV-positive mothers were: (1) fear of disclosing their HIV status to their children; (2) fear of infecting their children through casual contact, even though most women understood this was not how HIV/AIDS was transmitted; and (3) the impact of the illness on their ability to raise their children, both in the present and in the future, when they may not be available to care for their children themselves. (Faithfull, 1997).

In order to meet the multiple needs of HIV/AIDS mothers, specialized programs need to be developed that address the pragmatic issues of living with HIV/AIDS (i.e., health care, housing, child care) in coordination with social and emotional supports to help mothers through a time of loss, mourning, and isolation. While mothers with mental illness dealing with HIV/AIDS present further unique circumstances, the basic premise remains the same.

SUMMARY: Women represent the fastest growing cohort for HIV infection in the U.S. Women with mental illness are at increased risk for HIV infection. Research, policy and program initiatives have traditionally ignored the multiple needs of HIV-infected mothers with mental illness and their children. Lack of coordination around women's health concerns results in the inability to provide appropriate services and supports.

RECOMMENDATIONS: Given that women with mental illness disproportionately experience problems of substance abuse, violence, trauma, and HIV/AIDS, it is crucial to address these concerns through comprehensive, multidisciplinary treatment approaches. Integrated health, mental health, substance abuse, and trauma services that address the physical and mental health and well-being of women and their families would benefit women and children living with multiple vulnerabilities.

\section{Criminal Justice: Women in Prison and Jail}

Three out of every four incarcerated women have children (Johnston, 1991; Stanton, 1980), accounting for approximately 145,000 children in the United States with a mother in jail or prison (Gillard \& Beck, 1998; Johnston, 1995). As the incarcerated population continues to increase by approximately $6.5 \%$ a year (Gillard \& Beck), the number of children with mothers in prison will also increase. Seventy percent of these children live with grandparents or other relatives (Johnston).

The prevalence of mental illness in the female jail population is significantly higher than that of the general population. Over $80 \%$ of a randomly selected, stratified sample of 1271 female jail detainees in Chicago met criteria for one or more lifetime psychiatric disorders, the 
most common being substance use or dependence and posttraumatic stress disorder (Teplin, Abram \& McClelland, 1996). Major depressive episode and dysthymia are extremely prevalent. Teplin and collagues indicate the predominance of PTSD among female detainees, most likely related to the high rates of violent victimization, suggest and important, largely unmet aspect of their mental health needs.

Incarcerated women, specifically mothers with mental health issues, are underserved. The majority of services and programs offered in prison are based on models originally designed to serve men. As a result, many of the unique concerns and needs of women and mothers remain unaddressed. For example, few prisons and jails facilitate or support on-going relationships between mothers and their children. The role of motherhood for incarcerated women does not end upon entry into jail or prison. In fact, key informants report that motherhood remains the central focus of the lives of many incarcerated women. This creates a prime opportunity and, possibly, motivation for rehabilitation.

Innovative programs focus on the needs of incarcerated women as mothers. In Washington, DC, the Family Literacy Project brings children and women prisoners together to read books. This provides story time for the children, improves the literacy rates of the women, and gives families a chance to participate in normalizing activities. The Neil J. Houston House, in Boston, Massachusetts, is a pre-release program where women in the criminal justice system with substance abuse problems live with their young children. In this setting, motherhood is central to treatment. The Maryland Correctional Institution for Women (MCIW) hosts a program run by the Girl Scouts of Maryland and the National Institute of Justice. Troop meetings are held twice monthly at the MCIW where mothers and daughters discuss issues of relationships, substance abuse, teenage pregnancy and self-esteem. The Bedford Hills Correctional Facility in New York operates a nursery program with approximately 25 beds. Babies born to female inmates live with their mothers on the nursery floor of the prison hospital for up to one year. The children of women with more time to serve are placed with relatives or in foster care (Gabel \& Johnston, 1995).

While mental health services are acknowledged as an integral piece of treatment for incarcerated women (Teplin et al., 1996), one key informant noted that admission into these special programs for mothers may not be available to women with psychiatric diagnoses or receiving mental health services. Programs for incarcerated mothers must therefore be creative in their approaches to meeting the needs of women with mental illness. In addition, key informants indicate that mothers with mental illness in the criminal justice system experience and have to cope with the issues of loss and frustration common to all mothers separated from their children.

Similar to the research on outcomes for children whose parents have mental illness, most of the research on children of prisoners has focused on their problems, though researchers have found that all have areas of strength (Johnston, 1995). Three factors were identified by Johnston as consistent themes for children of incarcerated parents - parent-child separation, enduring traumatic stress, and an inadequate quality of care (Johnston, 1992). In addition, stigma and shame are important issues for children of prisoners (Gabel \& Johnston, 1995). Many children of incarcerated parents enter the child welfare system for foster care services, as placement with relatives or friends may not be possible (Norman, 1995). The Child Welfare League of America has focused on the needs of these children and families. (See for example, the special issue of the Child Welfare Journal on Children with Parents in Prison, September/October 1998, and Wright \& Seymour, 2000.) 
Phillips and Harm (2001), authors of a National Association for Family Based Services report on the needs of children of incarcerated mothers, recommend that children need a safe, stable environment free from further trauma, crisis intervention and case management services, and support groups. Their mothers benefit from interventions targeting their understanding of their rights and responsibilities as parents, and that address substance abuse, domestic violence, and child abuse/neglect; parent support programs and parent skills classes are recommended. The authors conclude that employment, housing and financial assistance are components of a comprehensive approach to the reunification of mothers and children following incarceration.

SUMMARY: The majority of women incarcerated in the U.S. are mothers; many have mental health issues and service needs. Mothers in jails and prisons often are not supported in their role as parent. Separation from one's children is a tremendous loss for a woman. According to key informants, the ability to parent one's children is a central focus and rehabilitation goal for many incarcerated mothers. Comprehensive programs for incarcerated mothers and their children may not be available, particularly to women with known mental health problems. As with other populations described in this section, the issues and needs of incarcerated parents and their children have considerable overlap with those of parents living with mental illness and their families.

RECOMMENDATIONS: Prisons and jails should adopt a preventive and/or rehabilitative approach with pregnant and parenting women, and address the special issues and needs of mothers with mental illness and their children. Failure to tap into the rehabilitative opportunities of serving time does a disservice to women, their families and society at large, since few women remain incarcerated their entire lives. Women can benefit from parenting education and skills development while incarcerated. Strategies developed for working with mothers in the criminal justice system and their children may be applicable to working with mothers with mental illness and their families in the mental health system, given the overlap in populations and similarity of circumstances and needs, particularly for those parents hospitalized in psychiatric facilities. While the focus of this work has been on mothers, the issues and needs of incarcerated men and those with mental illness who are fathers should not be ignored.

\section{Psychosocial Rehabilitation}

In the past two decades, psychosocial rehabilitation (PSR) services for adults with mental illness have become an increasingly important component of comprehensive mental health services. The goals of PSR services are to help those with mental illness participate optimally in their chosen adult life roles. PSR services are guided by a philosophy that stresses client choice

and empowerment, places an emphasis on client strengths, promotes community integration, and provides on-going services in the context of a client-provider relationship characterized by partnership and advocacy (Cook et al., 1996).

PSR interventions use either of two general approaches: (1) skills training approaches that aim to enhance the capacity of individuals with mental illness to perform the tasks and activities required of their chosen life roles; and (2) environmental modification approaches that aim to provide or enhance resources and supports, and/or reduce barriers so that individuals with mental illness may participate optimally in the living, learning, working and socializing environment of their choice. Many PSR services incorporate both approaches (Anthony, Cohen \& Farkas, 1990; Mueser, Drake \& Bond, 1997). 
A range of PSR services are effective in enhancing role participation among adults with mental illness. These include supported employment, education and housing services, intensive case management services, life skills (e.g. social, recreational, pre-vocational) training approaches, medication and stress management approaches, and psychoeducation for consumers and family members (Baron, 1998; Collins, Bybee \& Mowbray, 1998; Mueser et al., 1997). With its emphasis on optimal participation in normal adult life roles, PSR holds promise as a guiding framework for services for parents with mental illness. Yet, parenting as a life role has been largely ignored by PSR service providers (Nicholson \& Blanch, 1994). While specific services that support participation in life roles, such as employment, have existed for many years, analogous services to support parenting have not been developed within the field.

The potential of PSR approaches to services for parents with mental illness has been noted. Nicholson and Blanch (1994) argue for a comprehensive approach to services that includes assessment of parenting capacities, involvement of the parent in decisions regarding pregnancy and parenting status, efforts to help parents develop effective parenting skills, and the development of both informal and formal supports to enhance clients' capacity to parent. In a review of interventions for mothers with serious mental illness, Oyserman, Mowbray and Zemencuk (1994) maintain that services reflecting a PSR philosophy must: 1) assess mothers' environments, including quality of housing, social networks, and the availability of social/emotional supports, 2) assess mothers' strengths and the meaning of parenting for women with serious mental illness, 3) assess barriers to service participation and attainment of parenting goals. More recently, Nicholson and Henry (in press) suggest that targets of rehabilitation interventions should be determined in partnership with mothers, through assessment and consideration of mothers' parenting goals.

Few PSR agencies have developed services or programs specifically for parents with mental illness. One of the oldest and most well known programs is the Mothers' Project at Thresholds, a comprehensive PSR agency in Chicago (Zeitz, 1995). The Mothers' Project provides comprehensive center, community and home-based services for mothers with mental illness and their "at risk" children up to the age of 5. Children attend a therapeutic nursery program that emphasizes social-emotional and cognitive development; mothers participate in the nursery program where appropriate parenting skills are modeled. In addition, mothers are provided comprehensive case management services and can take advantage of a full array of PSR services, including supports for employment, recreation, education, and life skills training. Support services for other family members (e.g., fathers, grandparents) are also provided. As noted in the section of this paper on Child Outcomes and Therapeutic Intervention, evaluation of the Mother's Project has revealed promising outcomes for mothers and children.

There are likely many reasons why PSR agencies are not adequately addressing the needs of parents with serious mental illness and their children. These may include an actual lack of information about the parenting status of program clients, and a lack of knowledge among PSR providers regarding approaches to support parents. Parenting supports are rarely mandated in publicly funded PSR agencies, thus resources for such initiatives are limited. Moreover, many states have separate adult and child funding streams, precluding the provision of integrated services to parents and children by PSR agencies funded to serve adults. Lastly, clients in PSR agencies may be reluctant to seek help with parenting because they fear possible custody loss of their children. 
SUMMARY: Parenting is a primary and critical life role for many women and men with mental illness that must be acknowledged within the milieu of psychosocial rehabilitation. The PSR approach has a good track record in supporting adults with mental illness in developing skills in other life roles, and holds great potential for supporting the development of parenting skills among adults with mental illness.

RECOMMENDATIONS: Prioritize parenting as a fundamental life role, much like employment or participation in social networks, with a focus on identifying strengths that can be incorporated into a comprehensive approach to rehabilitation services.

\section{Legal System}

Having a mental illness is an added disadvantage in the legal system. Basic civil rights such as the right to vote or serve jury duty can be denied simply based on the diagnosis of a mental illness (Burton, 1990). In many states, the diagnosis of mental illness alone justifies the removal of children from their parents' care, and the termination of parental rights (Burton).

The determination of "parental competence" or the impact of a particular parent's mental illness on his or her capacity to parent, is complicated by the lack of an accepted definition, the irrelevance of traditional psychological instruments, situational influences, and the lack of normative data (Budd \& Holdsworth, 1996; Grisso, 1988). Concerns have been raised regarding the use of parent evaluations in child protection decisions (Budd, Poindexter, Felix, \& NaikPolan, 2001). These authors found numerous substantive limitations in the comprehensiveness and content of parent assessments in a sample of 190 mental health evaluations performed in conjunction with a major urban juvenile court system. Bias regarding mental illness and parenting may be introduced into the Court's findings (Davis \& Barua, 1995). Decisions with great consequence for adults and children are made with little basis in science, and are subject to much individual discretion (Hester, 1992; also see, generally, Daubert v. Merrell Dow Pharmaceuticals, Inc. 509 U.S. 579, 1993). Comprehensive multidisciplinary evaluation team models are recommended, but may be difficult to fund or staff (Budd et al., 2001; Jacobsen, Miller \& Kirkwood, 1997).

Key informants in the legal arena observed that a parent's diagnosis of mental illness can have a profound impact in divorce proceedings when custody and visitation determinations are made. Divorcing parents are faced with multiple stressors including the trauma of loss, grief, and financial burdens, which are usually more extreme for women than for men. Key informants suggested that mothers experiencing mental illness, particularly those whose ability to maintain employment is compromised, are often unable to afford the costs of divorce, e.g., lawyers fees, evaluations for the children, child care, missed work, and are therefore at a disadvantage. Many lawyers are reluctant to take divorce or custody cases where a parent has a mental illness. Most often this fear stems from a lack of knowledge about mental illness and how this relates to a person's ability to be a good parent. Situations where supervised visitation is necessary are also problematic because supervisors are both costly and difficult to find.

New England is home to efforts beginning to address the issues of adequate representation for individuals with mental illness in family law matters. The Clubhouse Family Legal Support Project in Massachusetts is co-led by Employment Options, Inc., a psychiatric rehabilitation clubhouse, and the Massachusetts Mental Health Legal Advisors Committee. A legal fellow, co-funded by the Massachusetts Bar Association and the National Association of Public Interest Lawyers, represents the needs of parents with mental illness, specifically those at 
risk of losing custody or contact with their children. As a staff member in the clubhouse, the legal fellow handles a variety of situations including custody and visitation issues, dealing with restraining orders, and negotiating housing issues that may mitigate against families reuniting. Funding also provides for the training of attorneys and judges regarding parental competence and mental illness.

In New Hampshire, the Disability Rights Center, and the Department of Health and Human Services Division of Behavioral Health are working together with peer support representatives, mental health consumers, the NH Bar's Legal Services program and Family Law Section; NAMI-NH; LARC; New Hampshire Children's Alliance; Child and Family Services of $\mathrm{NH}$; the Institute on Disability of the University of New Hampshire; the Division of Children, Youth and Families; Dartmouth Psychiatric Research; and private attorneys with family law practices as the Coalition for Family Law and Mental Health (Sanford, 2000). The purpose of the Coalition is to increase the availability of attorneys for individuals with mental illness who have family law issues; and to make reforms in the family court system in New Hampshire. Funding has been obtained from the NH Bar Foundation, NH Charitable Foundation, the Division of Behavioral Health and the Division of Children and Youth Services to support the hiring of a director, and to focus on increased education and training.

SUMMARY: Adults with mental illness, and particularly those who are parents, are at a disadvantage in the legal system. Because of the stigma attached to mental illness, general ignorance of the true impact of mental illness on day-to-day functioning, and the lack of appropriate evaluation methods, assumptions and decisions are made that may not be based in fact or supported by science. There is a lack of knowledge about the legal rights of adults with mental illness. Existing laws often work against parents with mental illness, whose access to their children may be denied, simply by virtue of their being labeled with a psychiatric diagnosis.

RECOMMENDATIONS: Create a standardized training model to educate lawyers and judges regarding the abilities of parents with mental illness and the needs of their children, and the rights of adults with mental illness and their families, specifically as they relate to custody, visitation and divorce. Provide accessible and affordable legal services to adults with mental illness. Develop the empirical foundation and relevant assessment procedures essential to improved parent evaluation practice. 


\section{Chapter VII}

\section{Programs for Parents with Mental Illness and their Families}

CRITICAL ISSUE: A small number of innovative programs have been developed in the U.S. and other countries over the past 20 years. The lack of standardized evaluation data across programs limits conclusions about best practices. In areas where there are no programs designed specifically to serve parents with mental illness, providers and families may piece together a patchwork of services. These may be poorly funded and difficult to maintain over time.

\section{The UMMS Program Survey}

Parents with mental illness are confronted with many barriers to receiving much needed support and services. Programs for families in which a parent has a mental illness are similarly confronted with multiple obstacles. None-the-less, promising programs have been developed in the U.S. and other countries over the last 20 years, though they are small in number (Cowling, 1999; Gold Award, 1996, 2000; Nicholson et al., unpublished raw data; Oyserman et al., 1994).

A recent mail survey to the UMMS National Network mailing list of programs and providers of services for parents with mental illness in the U.S., indicated that there are at least 50 programs for parents with mental illness. Of these programs, approximately 25 were designed specifically for parents with mental illness ("high specificity"). The remaining 25 programs serve parents with mental illness among their participants, but were designed and developed for a different population, e.g., adults with mental illness, homeless parents, parents at risk for loss of child custody. In addition to these programs that were able to be documented, it is likely that providers and families living where there are no programs, have pieced together a patchwork of services that were not designed explicitly to address parenting and family issues, but, of necessity, are doing so.

\section{Program Similarities}

Phone interviews with the directors from the 25 "high specificity" programs revealed both similarities and differences across programs. With respect to similarities, programs were reported to have developed from the recognition that parents with mental illness exist, and that traditional services were not addressing the needs of this group. In most cases, programs were pioneered and sustained by a dedicated individual or team who was firmly committed to serving this population, and to advocating for continued political and financial support. All programs shared a belief in the capacity of adults with mental illness to be parents, and a mission to support and actualize this capacity. Programs simultaneously acknowledged that needs of families in which a parent has a mental illness were complex, required coordination of multiple services, and that provision of these services was fraught with barriers. In particular, providers uniformly reported that mental health systems designed to serve individuals were not well-suited or responsive to families. Categorical and insufficient funding, and inappropriate and inadequate services were noted in particular. All programs shared the goals of 1) addressing basic needs such as housing and financial support, 2) improving parents' coping and problem-solving skills, 3) improving parenting skills specifically, and 4) enhancing child development. However, as will be discussed below, the relative emphasis on each of these goals, and the particular interventions implemented to achieve these goals, differed across programs. 


\section{Program Differences}

With respect to differences, programs reflected different developmental and funding histories, which in turn related to differences in theoretical orientation. Programs represented three basic historical origins. One group of programs developed primarily from within the adult mental health system in response to the recognition that many consumers were also parents, and that they needed services and supports to address this social role. A second group of programs developed primarily in the child welfare system that recognized that a large proportion of referred children had parents with significant mental health issues, and that these issues affected the child welfare system's ability to help families. A third group developed from inpatient psychiatry units that were confronted with the management of hospitalized pregnant women and a dearth of available community services to which they could refer upon discharge. In addition to these pathways, programs also developed from state and city homelessness and substance abuse programs.

Differences in historical and current funding sources appeared to be related to differences in theoretical orientation and design. Most programs reported an eclectic, pragmatic orientation toward services and treatment, based on clinical experience and/or available funding. Few programs reported a foundation in theoretical literature or systematic integration of research. Programs funded via the adult mental health system were likely to emphasize case management, assistance, and psychiatric rehabilitation, interventions valued by this system. By contrast, programs funded by the child welfare system often reflected a focus on attachment, parenting and child development, and were more likely to use models that included family/dyadic therapy as opposed to comprehensive service coordination. Inpatient and hospital-based programs provided medical and psychosocial services during an inpatient stay, and referral to community services after discharge, as reimbursable from third-party payers. Many programs were forced to seek multiple funding sources over time, a necessity that has fragmented services in some locations, but created blended, non-categorical funding streams, and interagency collaboration that better serves families in other locations.

Programs were extremely diverse in the services and interventions provided. They did not form neat groups, but could be distinguished on two fundamental and related dimensions: comprehensiveness and family-centeredness. Comprehensiveness refers to the degree to which a program was developed and designed to support the multiple needs of parents with mental illness, e.g., mental health needs and parenting needs. Family-centeredness reflects the degree to which the program was developed and designed to serve the family as a unit, rather than the parent or the child as an individual. Interviews with providers indicated that higher levels of comprehensiveness were related to higher levels of family-centeredness. This is not surprising, as the effort to support a family that involves many members, each with shared and individual needs, is likely to involve a greater number of services than providing support to an individual.

Differences across programs in comprehensiveness and family-centeredness appeared to be related to types of services provided, and the treatment mode in which they were provided. More comprehensive programs generally involved a case management, home-based approach. Coordination of services and collaboration with multiple providers were essential to supporting families effectively. Programs among the high and lower specificity groups that were unable to provide or access these components expressed frustration, and burn-out.

Finally, although programs shared the basic goal of supporting families in which a parent has a mental illness, targeted outcomes differed. Several programs had very specific and 
concrete goals, such as improving parent-child communication, or increasing a parent's understanding of child development. Other programs focused more singularly on functional adaptation of the parent, and fulfillment of necessary adult roles, of which parenting was one. More comprehensive programs often targeted loftier goals, such as enhancing the quality of life for all family members, by supporting the development of multiple life skills and illness management, in addition to parenting. Several programs that worked closely with the child welfare system focused on family preservation and/or reunification, and provided a range of services related to the accomplishment of that goal.

\section{Limited Evaluation Resources}

Unfortunately, programs reported that they had very limited resources for evaluation. Outcome data were typically collected on variables related to agency mandate and to meet the requirements of specific funders. Most programs collected parent/child satisfaction data, and reported high levels of satisfaction. Client outcomes were generally captured in service plans, treatment goals, and progress, and most providers reported gains by most program participants. However, standardized, objective evaluation data on parents and their children that could be compared across programs or generalized to other populations were not collected by programs. Therefore, an empirically-supported knowledge base of effective practices has not been developed.

Two Examples. Two programs provide noteworthy exception. Beardslee and colleagues have developed an intervention for families and children ages 8 to 15 years, in which one of the parents has had a recent hospitalization for an affective diagnosis (Beardslee et al., 1996b, 1997a, 1997c). Based on the literature of risk and resilience, the intervention uses a psychoeducational approach to educate parents about the potential impact of their illness on children, and to enhance communication between parents and children about mental illness. The importance of distancing the child's self-concept from the parent's illness is emphasized in an effort to support resiliency among children. Longitudinal follow-up of approximately 40 families indicated the intervention has been effective using both a clinician-based family therapy, and non-clinician didactic model (Beardslee et al., 1997a, 1997b, 1997c). Parents and children reported improved knowledge and communication about mental illness. Parents reported increased marital support and better understanding of each other's feelings. In addition, children reported improved understanding of parental disorder, and better overall functioning after the intervention (Beardslee et al., 1997c).

Using a very different approach, Musick et al. (1987) have developed a therapeutic nursery model for children aged $0-5$ years who have a mother with a mental illness. The focus of their intervention is on providing a stimulating environment that fosters child growth and development, along side parent coaching. Analyses of developmental scores indicate that children are improving and achieving development. Differences between children appear to be related to differences in caretaking behavior by their parents. Children who did better had mothers who showed some ability to see the child as a separate individual and to support his or her growth and development even when doing so was inconsistent with the mother's own needs. Success for children was also associated with more positive mood, reciprocity, and emotional responsiveness. In addition, resilient children had higher functioning and more supportive family networks, including an available and involved father. 
SUMMARY: Despite the existence of innovative and promising programs, there are few programs relative to the need, given the prevalence rates suggested by epidemiological data.

Program providers have great difficulty finding and sustaining funding, and continue to struggle with systems using categorical funding structures ill-suited to family-centered services. As a result, programs reflect the approaches of their primary funding sources and may lack the flexibility and/or comprehensiveness needed by this population. Finally, research literature has not been systematically integrated into program conceptualization, development, and design; and evaluation data have not been collected to allow for the development of empirically-supported services. As a result, outcomes for individuals and families may be severely compromised.

RECOMMENDATIONS: Programs for parents with mental illness and their families must be developed, driven by theory and research as well as funding source. Mechanisms need to be created that allow for interagency collaboration, and blended funding streams between adult and child mental health systems, and across the mental health, child welfare and other relevant systems. Programs for families in which a parent has a mental illness need to be described in theory and practice; and outcomes for adults and children need to be operationalized, and empirically assessed in both the short- and long-term. Strategies for program evaluation need to be developed and funded so programs can be tested and replicated effectively. 


\section{Chapter VIII}

\section{Steps for Stakeholders: A Consumer-Researcher's Perspective Lawrence Stier, Research Assistant}

Stakeholders have a unique opportunity to promote positive outcomes for parents with mental illness and their families. It is crucial that people on the receiving end of services and policies - parents and their families, inform this process. Parents can speak best to their needs and the needs of their children. Below are steps that all stakeholders must consider when thinking about the issues of parents with mental illness and their children.

Identify Adults with Mental Illness who are Parents. Are you a parent? This question should be asked of all adults with mental illness. Presently there is no standardized method of state or national data collection on the parenting status of adult clients with a psychiatric diagnosis. In addition, the limited data currently available are usually collected only on female clients. We often fail to recognize that male clients are parents too.

Identifying clients as parents and providing necessary supports can enhance parenting skills, bring a family together, and often assist in a client's recovery. Information should be collected on men and women in the public and private sectors. Questions should be asked that not only identify a client as a parent, but also identify the specific service needs of that parent. This data will show the variety of custodial issues and parenting concerns a parent may be facing.

Recognize the Strengths of Parents. Parents may not be aware of the strengths they bring to the parental role, choosing instead to dwell on the negative. It is important to recognize that all parents struggle with issues relating to raising children. In some cases they may feel they are failing as a parent. The question is how to help parents become aware of their strengths. Recognition of the hard work involved in raising children is important. Emphasizing strengths in parenting skills and acknowledging successes give parents a feeling of pride in their accomplishments. Any parent can identify with the enormous amount of time and energy that is expended raising a family.

Battle the Stigma of Mental Illness. In general, it seems that society feels that a person with mental illness should not be a parent, i.e., that a person with mental illness is incapable of raising and caring for a child. But in many cases, the exact opposite is true. Family unity is a key factor in treatment planning for both parents and children and can often accelerate recovery and improve outcomes for parents and children. Except in cases where a child's safety or welfare may be jeopardized, a person with mental illness should be allowed the opportunity to parent his or her children, and raise a family.

Attend to Custody and Visitation Issues. Parents who will be appearing in court, to retain or obtain custody of their children, should be supported in preparing, and should be encouraged to have a wellness plan in place. How they appear in court, how they take care of themselves, and what they are doing or plan to do to care for their children is their responsibility. If parents temporarily lose custody, they should request a time line for regularly scheduled evaluation or progress reports to determine their capabilities as a custodial parent. Should they lose custody of their children, they should request that this not be permanent. Parents and their advocates should outline a treatment or service plan that includes regaining custody as one of the plan's objectives. This plan should be available to all parties involved so everyone is aware of what actions parents intend to take to regain custody. 
Non-custodial parents may have a limited visitation schedule. Parents are often unsure of how to fully utilize visitation time with their children. Parents are concerned about "What is the best activity to fill this visit?" and "How do I entertain my children on a limited income?" Attention must be paid to how parents cope with their feelings about seeing their children on a limited basis when they want to, and may need to, spend more time with their sons and daughters.

How separation affects children must also be considered. Children separated from a parent may feel abandoned, seeing their parent only occasionally or not at all. In some cases there are no provisions for child visitation. When children do visit mental health facilities, there are usually restrictions on where visits can take place and for how long. Cheerful and safe areas should be provided in all mental health facilities for family visitation. For many children this may be the only avenue to seeing and knowing their parents.

Attend to Termination of Parental Rights Issues. A person with mental illness may have his or her parental rights terminated. This can result in parents feeling inadequate, and that they have lost contact with their children forever. Careful consideration needs to be given to whether the termination of parental rights is really in the best interest of a child. If the child is adopted, the prospect of open adoption should be considered. If a parent's rights are terminated, parents will need a forum to deal with feelings and concerns. A peer-to-peer, parent support group, possibly organized by service providers, could provide a low cost forum for custodial and non-custodial parents to talk about their experiences. This would provide a safe environment for parents to ask questions. A parent support group run by parents allows parents the opportunity to share difficulties they may be having, and to see how other parents have handled similar situations.

Attend to the Legal Issues of Parents. Parents need help with legal representation, which should be available on a low cost, or no-cost basis, if necessary. Attorneys sensitive to the issues and rights of persons with mental illness must be available. Emphasis should be placed on the need to keep families together, and the reunification of divided families.

Provide Supports for Children of Parents with Mental Illness. Children of parents with mental illness experience a variety of difficult emotions and life experiences, and may encounter many barriers to "normal" living. Much like adults, children experience feelings of guilt, blame and shame. These feelings may be amplified in children, who are less likely to realize which feelings are based in fact, and which are products of the stigma associated with having a parent with mental illness. A child may feel her actions and conversations could trigger, or even be responsible for her parent's relapse. Children may be hesitant to bring home friends or talk about their parents' illnesses.

Where do children discuss the feelings they have about dealing with a parent with mental illness? How do children understand what their mother or father is going through? Why parents act the way they do? How do children explain their family situation to their peers? Should the process of dealing with these feelings and questions be limited to therapy sessions with a provider whom they may never trust sufficiently? A forum for these children is needed.

A support group similar to Alateen could help children answer these questions. The group's agenda would be specific to children of parents with mental illness. Groups should be age sensitive; older children may understand and cope with feelings differently than younger children. Traditional counseling sessions do not necessarily afford children the opportunity to process their true feelings about parents' mental illnesses. 
Educate Professionals to the Needs of Parents. There should be a major effort to educate mental health workers, the court system, and the legal community about the needs of parents with mental illness. Dollars should be allocated to programs instructing parents in parenting skills and providing parent support. Support programs are also needed for noncustodial parents. In most cases, these should be two separate groups since the feelings and problems of a custodial parent and non-custodial parent can differ greatly.

Stakeholders must be educated about conditions that can exist in a parent-child relationship. Clients must be supported when struggling with parental rights issues, and be consoled if there is a loss of these rights. Support must be provided for both custodial and noncustodial parents. Becoming sensitive to the issues of being a parent with mental illness will strengthen the bond between advocate and client.

Peer Supports for Parents. Raising children can be very stressful. A psychiatric diagnosis can make parenting more difficult, and sometimes parents can feel overwhelmed. Parents may be concerned about the emotional or behavioral problems of their children. Parents may have issues regarding child rearing, visitation and custody -- questions that are often difficult to discuss with professionals from the adult mental health or child welfare system. Parents may feel frustrated, and sometimes angry, when they do not understand the important issues raised by child welfare workers related to their children. Parents with mental illness can become discouraged. They are often unable to find a voice regarding their needs as parents. Difficulties in parenting can be addressed by providing support groups and parenting training. These services, provided at a minimal cost, may be all that is required to alleviate most problems. Answers can be suggested and evaluated to aid parents in making difficult decisions.

A national parenting network with an 800 number and web site should be established. This would allow a parent access to parental support and information on a 24-hour-a-day basis. This parenting network could be used by any parent, but would be most useful to the parent with a mental illness. Chat rooms could be set up to discuss concerns. A parent could ask for help and direction during a crisis, such as having an ill child. All parents can appreciate the need for contact with other parents who can identify with a difficult situation.

Parenting as a Policy Priority. Federal and state policy makers should place the issues of parents high on their agenda. Legislation should be passed to ensure a parent his or her parental rights, giving parents with mental illness the same rights as any other parent. Currently, several states have policies whereby parental rights termination proceedings can be initiated based simply on a parent's psychiatric diagnosis. Policy makers need to realize that having a mental illness does not mean that a person is incapable of being a good parent, or of having a fulfilling and rewarding family life. In many cases, a family environment is better for raising a child then foster care or alternate living arrangements. Family unity can also aid the client's recovery since child-parent separation is often a cause for increased stress, anxiety, fear, and depression.

Coordinate Services for Parents. Agencies and service providers working with parents and their families need to communicate with each other. While privacy and confidentiality regulations must be respected, most parents want the coordination and may be willing to grant release of information if they see a clear benefit for themselves or their children. Coordination across agency boundaries should facilitate the provision of more appropriate services in a more cost-effective fashion. Priority should be placed on keeping families together and reuniting divided families. Family unity should be a priority in making decisions in both the child welfare and adult mental health care arenas. 
Parents with mental illness must seek support and legislation to guarantee their parental rights. Service providers should provide supports through parent education and skills training. Parents should insist on the coordination of services between child and adult service agencies, which should prioritize keeping families together while providing a family-friendly and safe environment. A parent must voice his or her needs and concerns in order to be a good parent. If these needs are not met, parents with mental illness can never achieve family unity and the goal of good parenting may be beyond their reach. 


\section{Chapter IX}

\section{Summary of Critical Issues and Recommendations}

The following is a summary of the critical issues for parents with mental illness and their families organized by the original questions posed for this project. Recommendations follow.

\section{The Critical Issues}

\section{- Question: Who are parents with mental illness and their families?}

- There are no comprehensive data regarding the parenting status of adults with mental illness and the family status of their children. However, preliminary analyses of National Comorbidity Survey data suggest that the majority of adults with a lifetime prevalence of mental illness are parents, and that adults with mental illness are at least as likely, if not more likely to be parents than those without mental illness.

- Without an understanding of the scope of the problem, services fully supportive of parents with mental illness and their families cannot be developed, and the implications of policies and practices cannot be fully determined. On a case by case basis, key informants report that federal and state policies and practices, and the lack of relevant services have profound negative effects on families living with mental illness.

- Question: What do we know about the experiences of adults with mental illness who are parents? What are their needs? What are the barriers to meeting their needs?

- Most of what we have learned in the past decade in the U.S. about the experiences of parents with mental illness is based on research with small samples of mothers in the public sector with severe mental illness and multiple other stressors such as poverty, and ethnic minority status.

- We know very little about the experiences of parents whose diagnoses fall across the full spectrum of psychiatric disorders, or who are white, middle class, and receive private sector services.

- We know virtually nothing about the characteristics or experiences of fathers with mental illness.

- The challenges of parents with mental illness have a great deal in common with those faced by all parents, though the literature has emphasized the unique circumstances of these parents and, most commonly, their deficits and failures.

- Stigma is a significant barrier to service utilization, as are aspects of the organization, administration, and funding of services, and the lack of integration or coordination of services across and within systems. 
- Question: What is the impact on children of having a parent with mental illness?

- Two decades of research have unequivocally indicated that children who have a parent with mental illness are at significantly greater risk for multiple psychosocial problems. Despite these risks, many children of parents will mental illness are resilient and appear to avoid significant problems

- Research has uncovered multiple sources of risk and resilience for children of parents with mental illness, although the focus in research has been on risk and negative outcomes, and not as often on sources of resilience and strengths. Most of the studies of resilience focus on children at risk of poor development due to environmental risk factors.

- No attention has been paid to children's subjective experiences or reports of what is useful to them in coping with their families' circumstances.

- Interventions have not been widely informed by new knowledge of the contribution of moderators to enhanced child outcomes.

\section{- Question: How do federal, state and local policies and practices impact these families?}

- Aspects of the Adoption and Safe Families Act of 1997, i.e., the time frames and dearth of appropriate services, may mitigate against maintaining or reunifying families in which parents have mental illness.

- To date, the Americans with Disabilities Act has afforded little protection to parents with mental illness, particularly in termination of parental rights proceedings.

- Without appropriate family and work supports to overcome barriers to employment, parents with mental illness, especially single mothers, may be unable to comply with PRWORA/TANF regulations, resulting in the loss of benefits to families and children in greatest need.

- Managed care organizations, including those managing public sector mental health benefits, may overlook the unique needs of their adult subscribers with mental illness who are parents in their standardized treatment authorization and utilization review processes, jeopardizing outcomes for parents and children.

- SMHAs that are unresponsive to the needs of adult clients who are parents and their children miss a prime opportunity to work towards recovery and wellness for families in the public sector, and may actually contribute to poor outcomes for both the adults and the children they serve. Fewer SMHAs today identify the parenting status of clients than did in 1990.

- Question: What can we learn from other service systems and fields to inform our research, policies and practice? 
- While parents with mental illness are found in studies of child welfare populations, and assumptions may be made by providers that parents with mental illness may possibly abuse or neglect their children, we do not know the prevalence of child abuse or neglect in families where parents have mental illness. Neither do we know much about the mental health needs of parents in the child welfare system. This lack of knowledge regarding the overlap of parental mental illness and child welfare involvement has significant implications for families affected by child welfare policy and practice, e.g., the Adoption and Safe Families Act. Equally critical are the likely effects of this lack of knowledge on families living with mental illness entering the legal system through the child welfare door.

- While children in families in which parents have mental illness are likely to be at developmental risk, Early Intervention or Head Start efforts have not systematically assessed or focused upon the needs of this possibly substantial subgroup of children and families. Opportunities for training and supporting these parents, and preventing and remediating their children's emotional difficulties and developmental delays may be overlooked.

- While there is most likely considerable overlap between the population of parents with substance abuse issues and those with mental illness, the knowledge gained in shifting substance abuse treatment paradigms from an individual client to a mother-child focus has not been widely applied in the mental health treatment arena.

- The impact of early traumatic experiences on the functioning of adults with mental illness as parents is unstudied and, frequently, not addressed in mental health assessment or treatment.

- Research, policy, and program initiatives have traditionally ignored the multiple needs of HIV-infected mothers with mental illness and their children.

- The majority of women in jails and prisons in the U.S. are mothers, many of whom have mental health issues. Motherhood and mental illness are neglected in the criminal justice system, though new programs for parents and children are emerging. While the experiences of parents and outcomes for children in families disrupted by parental incarceration, psychiatric hospitalization, or the removal of children by child protection agencies may be similar, there has been little transfer of knowledge among criminal justice, mental health, and child welfare systems about these issues.

- Parenting is a primary and critical life role for many women and men with mental illness that has not been acknowledged fully within the milieu of psychosocial rehabilitation (PSR). Consequently adults with mental illness have not benefited widely from PSR approaches that could be targeted to enhancing their functioning as parents.

- Because of the stigma attached to mental illness, general ignorance of the true impact of mental illness on day-to-day parental functioning, and the lack of appropriate evaluation 
methods, assumptions and decisions are made about parents with mental illness in the legal system that may not be based in fact or supported by science.

\section{- Question: Are there effective program models to enhance outcomes for parents with mental illness and their children?}

- Despite innovative and promising efforts, there are few programs for parents with mental illness and their children, relative to the need, that are driven by theory and research, have stable funding, and are well-evaluated.

\section{Recommendations}

Systems. National prevalence data must be obtained on the parenting status of adults with mental illness and the family status of their children, i.e., custody, residential status, caregiving arrangements. The issue is not simply whether or a not a person with mental illness is a parent. Comprehensive questions must be asked regarding household composition, custody status, and care arrangements. The full range of characteristics and experience of parents and children must be described, including those of fathers, families in the private sector, and of individuals with various psychiatric diagnoses. A flexible definition of family must be built into research to reflect the possible diversity of formal and informal care giving arrangements for children, particularly given probable socioeconomic, and racial/ethnic differences in family networks and patterns of care giving. Previously collected, large data sets, like the National Comorbidity Survey (NCS) or the National Health Interview Survey (NHIS), could be analyzed using available items related to mental illness, parenting status, and family and risk characteristics to begin to address research questions. On-going national data collection efforts, like the NCS and the NHIS, must be reviewed and modified to include questions that capture this information. New data collection efforts must be supported.

The experiences of children whose parents have mental illness must be explored, and opportunities for subjective reporting provided to children of different ages and developmental stages to obtain information on children's experiences in the current treatment, rehabilitation and advocacy climate. Much of our knowledge of children's experiences comes from individuals who are currently adults, who grew up in times of less effective treatment and lengthy hospitalizations. Our recent knowledge of outcomes for children is based largely on studies of white, middle-class families, with mothers diagnosed with depression. Research must reflect the diversity of American families, psychiatric disorders, and contemporary treatment and rehabilitation approaches, and capture strengths and sources of resilience as well as deficits and factors contributing to negative outcomes for children and parents.

Research must be conducted on the prevalence of child abuse and neglect among families in which parents have mental illness. Factors contributing to parents' success and reducing risk to children must be identified. The impact of childhood trauma and current violence on parents' functioning and their relationships with their children must be explored. The costs and benefits of family disruption, emotional and financial, must be documented to be factored into policy and practice decision-making. Services, and training and advocacy initiatives must be informed by research to adequately meet the needs of these vulnerable families, the range of whose circumstances seems to be poorly understood. 
Existing practices must be reviewed to consider more fully their impact on parents with mental illness and their families, and modified to take their varying characteristics and circumstances into account. The organization, administration and funding of mental health services must support the system's capacity to respond to family need whether the "identified client" is the adult or the child, and encourage a "family wrap-around" approach. Client eligibility requirements must be reviewed, and barriers to services to support full family functioning must be identified and overcome. SMHAs must take the lead in identifying clients as parents, considering the needs of families, and providing services to all family members living with serious mental illness.

There is much to be learned from other systems and fields, which can potentially be applied to mental health services and programs for parents and their families. Given the complex needs of these families, knowledge dissemination across systems is essential. For example, knowledge learned in the implementation and evaluation of child welfare family preservation models, Head Start, programs for incarcerated parents, substance abuse treatment initiatives, and efforts through the public health arena to support families with HIV/AIDS can inform the development of services and programs originating in the mental health arena.

Likewise, efforts in other systems and areas of practice must be informed by knowledge developed in the mental health arena regarding the circumstances and needs of families living with mental illness, and effective treatment and rehabilitation strategies for individuals with mental illness or serious emotional disturbance. Given the likely overlap in service populations among public sector systems of care and current gaps in services, efforts must be made to integrate and coordinate existing services and to develop innovative approaches to address the multiple vulnerabilities of these families. For example, families in which parents are living with mental illness may approach services through the primary care door. Parents may prioritize their children's needs, and bring children for well visits and acute care. Primary care physicians have the opportunity, if they are informed and have the appropriate tools and resources available, to intervene in the context of a non-stigmatizing, "normalizing" environment, engaging parents doing something "right," i.e., seeking appropriate health care for their children. Policy or program initiatives that fail to take whole families into account are doomed to be less effective and, most likely, more costly, as systems and services are set against each other, through duplicated, fragmented or simply inaccessible services, and conflicting mandates, incentives and treatment goals.

The needs of these families must be acknowledged and addressed in additional arenas where parents are likely to bring children for services, as well as in the private sector. Prevention and family strengthening approaches could be extremely successful in supporting families with young children, who are likely to access services routinely and earlier through venues other than mental health, e.g., primary care or preschool programs.

Services. Standardized service plans and treatment protocols must be studied and revised to overcome system-induced barriers to service utilization and treatment effectiveness. Review and modification of inter-agency agreements and vendor contracts would permit the inclusion of language and expectations for integrated, family-centered, strengths-based care for parents with mental illness and their children.

Existing programs must be described and evaluated. Several well-developed programs, specifically targeted to parents with mental illness and their families, could serve as models for replication. However, these programs require technical assistance and financial support to 
describe their efforts fully, i.e., document their theories of change and develop logic models, and to evaluate the process of service provision and outcomes for parents and children. Replication of effective models could be supported through existing funding mechanisms, e.g., community action grants. Innovations within mental health, e.g., psychosocial rehabilitation strategies for skills training and resource environment modification, should be applied to the domain of parenting. The development of new intervention strategies must be supported, e.g., efforts to integrate services and meet the mental health needs of families in primary care settings.

These efforts would benefit from coordinated federal initiatives, drawing on established links and creating new connections among agencies such as the SAMHSA Centers, the National Institute on Disability and Rehabilitation Research, the Office of Special Education and Rehabilitation, the Office of Criminal Justice, Maternal and Child Health, etc. Current federal initiatives, e.g., SAMHSA multi-site studies, could be supplemented to support investigation of factors contributing to resilience as well as risk, and the impact of interventions on all family members, adults and children.

Training and Advocacy. The significance of stigma as a barrier to the successful functioning of families living with mental illness cannot be overstated. Training and advocacy efforts must target all systems and domains in which families find themselves including the child welfare system, education and early intervention, the legal and criminal justice systems, public health and primary care. In each of these areas, policy makers, program planners, and providers make decisions on a daily basis with profound impact on parents with mental illness and their children, and tremendous impact on the service systems assembling resources to meet the needs of these families. The targets of training and advocacy efforts must include: child welfare workers, teachers, early intervention providers, lawyers, judges, law enforcement personnel, and health care professionals. Professionals and advocates must inform legislators and policy makers, as well as the general public, about the impact of their decisions on families in which parents have mental illness, and the potential opportunities for cost-savings through public awareness, education, prevention and early intervention.

Within the mental health arena, providers must acknowledge the significance of the parenting role to adults with mental illness, and the impact of parenting status on service utilization and treatment compliance for entire families. The responsibilities and needs of adults with mental illness as parents may conflict with the treatment regimes prescribed by clinicians. For example, a mother who has to fix breakfast and send her child off to school will not take medication that makes her lethargic in the morning, compromising her longer-term mental health to meet short-term goals. If a mother with mental illness does not have back-up child care, she will be extremely reluctant to be hospitalized, appearing to be resistant to providers' recommendations. Mental health professionals trained in traditional "adult" or "child" programs must be encouraged to consider the impact of family life on people they perceive as individual "patients," and the impact of mental illness and serious emotional disturbance on family life.

Advocates must work with families, parents and children, to overcome stigma within the family and the attitudes of parents themselves, which are often negative. Children live with the "secondary" stigma of having a parent with mental illness. They may be teased on the playground or embarrassed to bring friends home. Stigma and mental illness breed isolation. Family members want "normalizing" experiences that connect them with their peers, their neighbors, and the larger world. The development of a national advocacy network and peer 
supports may be key to promoting the well being and healthy functioning of parents with mental illness and their children.

Essential to training and advocacy efforts is the "buy in" of constituent groups traditionally considered as representing adults, parents, or children. We can no longer afford to focus on the needs of individual adults with mental illness or children with serious emotional disturbance, given the high probability that these individuals are, or want to be, living in families. Advocates must work together to bring attention to the needs and aspirations of whole families living with mental illness. 


\section{References}

Alexander, M.J. (1996). Women with co-occurring addictive and mental disorders: An emerging profile of vulnerability. American Journal of Orthospychiatry, 66(1), 61-69.

Alexander, M.J. \& Muenzenmaier, K. (1998). Trauma, addiction, and recovery: Addressing public health epidemics among women with severe mental illness. In B. L. Levin \& A. K. Blanch (Eds.), Womens Mental Health Services: A Public Health Perspective (pp. 215239). Thousand Oaks: Sage Publications, Inc.

Altshuler, L.L. \& Szuba, M.P. (1994). Course of psychiatric disorders in pregnancy. Neurologic Clinics, 12, 613-635.

Andrews, G., Stewart, G., Allen, R. \& Henderson, A. S. (1990). The genetics of six anxiety disorders: A twin study. Journal of Affective Disorders, 19, 23-29.

Anthony, W., Cohen, M., \& Farkas, M. (1990). Service systems. In W. A. Anthony, M. Cohen, \& M. Farkas (Eds.), Psychiatric Rehabilitation (pp. 169-193). Boston: Boston University.

Aruffo, J.F., Coverdale, J.H., Chacko, R.C. \& Dworkin, R.J. (1990). Knowledge about AIDS among women psychiatric outpatients. Hospital \& Community Psychiatry, 41(3), 326328.

Bachu, A. (1995). Fertility of American women. Washington, DC: U.S. Census Bureau.

Bachu, A. (1996). Fertility of American men: Population division working paper. Washington, DC: U.S. Bureau of the Census.

Baker, D.R. (2000). Reasonable efforts. Child Law Practice, 19(4), 51-54.

Barker, L.T. \& Maralani, V. (1997). Challenges and strategies of disabled parents: Findings from national survey of parents with disabilities. Oakland, CA: Berkeley Planning Associates.

Barocas, R., Seifer, R. \& Sameroff, A.J. (1985). Defining environmental risk: Multiple dimensions of psychological vulnerability. American Journal of Community Psychology, $\underline{13}, 433-447$.

Baron, R.C. (1998). The impact of behavioral managed care on employment programming for persons with serious mental illness. International Journal of Mental Health, 27(4), 41-72.

Baron, R.M. \& Kenny, D.A. (1986). The moderator-mediator variable distinction in social psychological research: Conceptual, strategic, and statistical considerations. Journal of Personality \& Social Psychology, 51(6), 1173-1182. 
Bassuk, E.L., Melnick, S. \& Browne, A. (1998). Responding to the needs of low-income and homeless women who are survivors of family violence. Journal of the American Medical Womens Association, 53(2), 57-64.

Beardslee, W.R., Keller, M.B., Seifer, R., Podorefsky, D., Staley, J., Lavori, P.W. \& Shera, D. (1996a). Prediction of adolescent affective disorder: Effects of prior parental affective disorders and child psychopathology. Journal of the American Academy of Child \& Adolescent Psychiatry, 35(3), 279-288.

Beardslee, W.R. \& Podorefsky, D. (1988). Resilient adolescents whose parents have serious affective and other psychiatric disorders: Importance of self-understanding and relationships. American Journal of Psychiatry, 145(1), 63-69.

Beardslee, W.R., Salt, P., Versage, E.M., Gladstone, T.R.G., Wright, E.J. \& Rothberg, P.C. (1997a). Sustained change in parents receiving preventive interventions for families with depression. American Journal of Psychiatry, 154(4), 510-515.

Beardslee, W., Versage, E., Wright, E., Salt, P., Rothberg, P.C., Drezner, K. \& Gladstone, T.R.G. (1997b). Examination of preventive interventions for families with depression: Evidence of change. Development \& Psychopathology, 9(1), 109-130.

Beardslee, W.R., Wright, E.J., Rothberg, P.C., Salt, P. \& Versage, E.M. (1996b). Response of families to two preventive intervention strategies: Long-term differences in behavior and attitude change. Journal of the American Academy of Child \& Adolescent Psychiatry, 35(6), 774-782.

Beardslee, W.R., Wright, E.J., Salt, P., Drezner, K., Gladstone, T.R.G., Versage, E.M. \& Rothberg, P.C. (1997c). Examination of children's responses to two preventive intervention strategies over time. Journal of the American Academy of Child \& Adolescent Psychiatry, 36(2), 196-204.

Beidel, D. C. \& Turner, S. M. (1997). At risk for anxiety: I. Psychopathology in the offspring of anxious parents. Journal of the American Academy of Child and Adolescent Psychiatry, $\underline{36}(7), 918-924$.

Biederman, J., Faraone, S.V., Hirshfield-Becker, D.R., Friedman, D., Robin, J.A. \& Rosenbaum J. F. (2001). Patterns of psychopathology and dysfunction in high-risk children of parents with panic disorder and major depression. American Journal of Psychiatry, $\underline{158}(1), 49-57$.

Billings, A.G. \& Moos, R.H. (1983). Comparisons of children of depressed and non-depressed parents: a social-environmental perspective. Journal of Abnormal Child Psychology, $\underline{11}(4), 483-486$.

Blanch, A.K., Nicholson, J. \& Purcell, J. (1994). Parents with severe mental illness and their children: The need for human services integration. Journal of Mental Health Administration, 21(4), 388-396. 
Bland, R.C. \& Orn, H. (1986). Psychiatric disorders, spouse abuse and child abuse. Psychiatric Disorders, 86(4), 444-449.

Bond, G.R., Drake, R.E., Becker, D.R. \& Mueser, K.T. (1999). Effectiveness of psychiatric rehabilitation approaches for employment of people with severe mental illness. $\underline{\text { Journal }}$ of Disability Policy Studies, 10(1), 18-52.

Brown, V.B., Sanchez, S., Zweben, J.E. \& Aly, T. (1996). Challenges in moving from a traditional therapeutic community to a women and children's TC model. Journal of Psychoactive Drugs, 28(1), 39-46.

Budd, K.S. \& Holdsworth, M.J. (1996). Issues in clinical assessment of minimal parenting competence. Journal of Clinical Child Psychology, 25(1), 2-14.

Budd, K.S., Poindexter, L.M., Felix, E.D. \& Naik-Polan, A.T. (2001). Clinical assessment of parents in child protection cases: An empirical analysis. Law and Human Behavior, $\underline{25}(1), 93-108$.

Burton, V.S. (1990). The consequences of official labels: A research note on rights lost by the mentally ill, mentally incompetent, and convicted felons. Community Mental Health Journal, 26(3), 267-276.

Canino, G.J., Bird, H.J., Rubio-Stipec, M., Bravo, M. \& Algeria, M. (1990). Children of parents with psychiatric disorder in the community. Journal of the American Academy of Child \& Adolescent Psychiatry, 29(5), 398-406.

Caplan, G. (1989). Prevention of psychopathology and maladjustment in children of divorce. In M.Brambring, F.Losel \& H.Skowronek (Eds.), Children at risk: Assessment, longitudinal research, and intervention. Prevention and intervention in childhood and adolescence (pp. 367-394). Berlin, Germany: Walter de Gruyter.

Carey, M.P., Weinhardt, L.S. \& Carey, K.B. (1995). Prevalence of infection with HIV among the seriously mentally ill: Review of research and implications for practice. Professional Psychology - Research \& Practice, 26(6), 262-268.

Caton, C.L., Cournos, F. \& Dominquez, B. (1999). Parenting and adjustment in schizophrenia. Psychiatric Services, 50, 232-243.

Centers for Disease Control (1999). HIV/AIDS surveillance report. Atlanta, GA: U.S. Department of Health and Human Services.

Centers for Disease Control (2000). HIV/AIDS among U.S. women: Minority and young women at continuing risk. Atlanta, GA: U.S. Department of Health and Human Services.

Chaffin, M., Kelleher, K. \& Hollenberg, J. (1996). Onset of physical abuse and neglect: Psychiatric, substance abuse, and social risk factors from prospective community data. Child Abuse \& Neglect, 20(3), 191-203. 
Children's Defense Fund (2000, December). Issue Basics, Adoption and Safe Families Act (ASFA). Action Council Brief.

Collins, M.E., Bybee, D. \& Mowbray, C.T. (1998). Effectiveness of supported education for individuals with psychiatric disabilities: Results from an experimental study. Community Mental Health Journal, 34(6), 595-613.

Cook, J. \& Steigman, P. (2000). Experiences of parents with mental illnesses and their service needs. The Journal of NAMI California, 11, 21-23.

Cook, J.A., Pickett, S.A., Razzano, L., Fitzgibbon, G., Jonikas, J.A. \& Cohler, J.J. (1996). Rehabilitation services for persons with schizophrenia. Psychiatric Annals, 26(2), 97104.

Corea, G. (1992). The invisible epidemic. New York: HarperCollins.

Coverdale, J.H., McCullough, L.B., Chervenak, F.A., Bayer, T. \& Weeks, S. (1997). Clinical implications of respect for autonomy in the psychiatric treatment of pregnant patients with depression. Psychiatric Services, 48(2), 209-212.

Cowling, V.(1999). Children of parents with mental illness ( $\left({ }^{\text {st }}\right.$ ed.). Melbourne: Axis Publishing Services.

Cox, A.D., Puckering, C., Pound, A. \& Millis, M. (1987). The impact of maternal depression in young children. Journal of Child Psychology and Psychiatry, 28(6), 917-928.

Cummings, E.M. \& Davies, P.T. (1994). Maternal depression and child development. Journal of Child Psychology and Psychiatry, 35, 73-112.

Davies, P.T. \& Windle, M. (1997). Gender-specific pathways between maternal depressive symptoms, family discord, and adolescent adjustment. Developmental Psychology, 33(4), 657-668.

Davis, P.C. \& Barua, G. (1995). Custodial choices for children at risk: Bias sequentially, and the law. Roundtable, 2, 139-159.

DeChillo, N., Koren, P. \& Schultze, K.H. (1994). From paternalism to partnership: Family and professional collaboration in children's mental health. American Journal of Orthopsychiatry, 64(4), 564-576.

Dickstein, S., Seifer, R., Hayden, L.C., Schiller, M., Keitner, G.I., Miller, I., Sameroff, A.J., Rasmussen, S., Matzko, M. \& Magee, K.D. (1998). Levels of family assessment: II. Impact of maternal psychopathology on family functioning. Journal of Family Psychology, 12(1), 23-40.

Dinwiddie, S.H. \& Bucholz, K.K. (1993). Psychiatric diagnoses of self-reported child abusers. Child Abuse \& Neglect, 17(4), 465-476. 
Downey, G. \& Coyne, J.C. (1990). Children of depressed parents: An integrative review. Psychological Bulletin, 108(1), 50-76.

Downey, G. \& Walker, E. (1989). Social cognition and adjustment in children at risk for psychopathology. Developmental Psychology, 25, 835-845.

Emery, R., Weintraub, S. \& Neale, J.M. (1982). Effects of marital discord on the school behavior of children of schizophrenic, affectively disordered, and normal parents. Journal of Abnormal Child Psychology, 10(2), 215-228.

Empfield, M.D. (2000). Pregnancy and schizophrenia. Psychiatric Annals, 30(1), 61-66.

Evans, C. \& Lacey, J.H. (1992). Multiple self-damaging behaviour among alcoholic women: A prevalence study. British Journal of Psychiatry, 161,(Nov.), 643-647.

Faithful, J. (1997). HIV-positive and AIDS-infected women: Challenges and difficulties to mothering. American Journal of Orthopsychiatric, 67(1), 144-151.

Famularo, R., Kinschereff, R. \& Fenton, T. (1992a). Parental substance abuse and the nature of child maltreatment. Child Abuse \& Neglect, 16(4), 475-483.

Famularo, R., Kinschereff, R. \& Fenton, T. (1992b). Psychiatric diagnoses of abusive mothers: A preliminary report. The Journal of Nervous and Mental Disease, 180, 658-661.

Fendrich, M., Warner, V. \& Weissman, M.M. (1990). Family risk factors, parental depression, and psychopathology in offspring. Developmental Psychology, 26(1), 40-50.

Finkelstein, N. (1993). Treatment programming for alcohol and drug-dependent pregnant women. International Journal of the Addictions, 28(13), 1275-1309.

Finkelstein, N. (1994). Treatment issues for alcohol and drug dependent pregnant and parenting women. Health and Social Work, 19(1), 7-15.

Finkelstein, N., Kennedy, C., et al. (1997, March). Gender Specific Substance Abuse Treatment. Alexandria, VA: National Women's Resource Center; Center for Substance Abuse Prevention/Substance Abuse \& Mental Health Services Administration.

Frankel, B. \& Hewitt, B. (2000, July 24). Surviving a mentally ill mother. People, 54(4), 55.

Friedman, R.M., Katz-Leavy, J., Manderscheid, R.W. \& Sondheimer, D.L. (1996). Prevalence of serious emotional disturbance in children and adolescents. Rockville: U.S. Department of Health and Human Services.

Gabel, K. \& Johnston, D. (1995). Children of Incarcerated Parents. New York: Lexington Books.

Gamache, G., Tessler, R.C. \& Nicholson, J. (1995). Child care as a neglected dimension of family burden research. Research in Community and Mental Health, 8, 63-90. 
Garber, J. \& Robinson, N. S. (1997). Cognitive vulnerability in children at risk for depression. Cognition and Emotion, 5/6, 619-635.

Gilliard, D.K. \& Beck, A. (1998, August). Prisoners in 1997. Washington, DC: U.S. Department of Justice, Bureau of Justice Statistics.

Glover, V., Teixeira, J., Gitua, R. \& Fisk, N. (1998, April). Links between antenatal maternal anxiety and the fetus. Paper presented at the $11^{\text {th }}$ Biennial Conference on Infant Studies, Atlanta, GA.

Gold Award (1996). Comprehensive prenatal and postpartum psychiatric care for women with severe mental illness - University of Illinois at Chicago Women's Program, Chicago. Psychiatric Services, 47(10), 1108-1111.

Gold Award (2000). Supportive residential services to reunite homeless mentally ill single parents with their children - The Emerson-Davis Family Development Center in Brooklyn, New York City. Psychiatric Services, 51(11), 1433-1435.

Goodman, L.A., Rosenberg, S.D., Mueser, K.T. \& Drake, R.E. (1997). Physical and sexual assault history in women with serious mental illness: Prevalence, correlates, treatment, and future research directions. Schizophrenia Bulletin, 23(4), 685-696.

Goodman, S.H. \& Brumley, H.E. (1990). Schizophrenic and depressed mothers: Relational deficits in parenting. Developmental Psychology, 26(1), 31-39.

Goodman, S.H. \& Gotlib, I.H. (1999). Risk for psychopathology in the children of depressed mothers: A developmental model for understanding mechanisms of transmission. Psychological Review, 106(3), 458-490.

Goodwin, F.K., Alfred, D.C., Coyle, J.T, et al. (1993). Health care reform for Americans with severe mental illness: Report of the National Advisory Mental Health Council. American Journal of Psychiatry, 150, 1447-1464.

Grisso, T. (1988). Evaluating Competencies: Forensic Assessments and Instruments. New York: Plenum Press.

Gross, D., Conrad, B., Fogg, L., Willis, L. \& Garvey, C. (1995). A longitudinal study of maternal depression and preschool children's mental health. Nursing Research, 44(2), 96-101.

Hammen, C. (1991). Depression runs in families: The social context of risk and resilience. New York: Springer.

Hammen, C., Burge, D. \& Adrian, C. (1991). Timing of mother and child depression in a longitudinal study of children at risk. Journal of Consulting and Clinical Psychology, 59(2), 341-345. 
Hammen, C., Burge, D. \& Stansbury, K. (1990). Relationship of mother and child variables to child outcomes in a high-risk sample: A causal modeling analysis. Developmental Psychology, 26(1), 24-30.

Hammen, C., Gordon, G., Burge, D., Adrian, C., Jaenicke, C. \& Hiroto, G. (1987). Maternal affective disorder, illness and stress: Risk for children's psychopathology. American Journal of Psychiatry, 144, 736-741.

Hanson, D.R., Gottesman, I.I. \& Meehl, P.E. (1977). Genetic theories and the validation of psychiatric diagnosis: Implications for the study of children of schizophrenics. Journal of Abnormal Psychology, 86, 575-588.

Harnish, J.D., Dodge, K.A., Valente, E. \& Conduct Problems Prevention Research Group (1995). Mother-child interaction quality as a partial mediator of the roles of maternal depressive symptomatology and socioeconomic status in the development of child behavior problems. Child Development, 66, 739-753.

Harris, M. \& Landis, C.L. (1997). Sexual abuse in the lives of women diagnosed with serious mental illness. New directions in therapeutic interventions (2nd ed.). The Netherlands: Harwood Academic Publishers.

Hearle, J., Plant, K., Jenner, L., Barkla, J. \& McGrath, J. (1999). A survey of contact with offspring and assistance with child care among parents with psychotic disorders. Psychiatric Services, 50(10), 1354-1356.

Helzer, J.E. \& Pryzbeck, T.R. (1994). The co-occurrence of alcoholism and other psychiatric disorders. In N. S. Miller (Ed.), Principles of addiction medicine (pp. 1-6). Chevy Chase, MD: American Society of Addiction Medicine, Inc.

Hester, T.J. (1992). The role of mental health professionals in child custody determinations incident to divorce. Women's Rights Law Reporter, 14, 109-122.

Hops, H. (1996). Intergenerational transmission of depressive symptoms: Gender and developmental considerations. In C. E. Mundt \& M. J. Goldstein (Eds.), Interpersonal factors in the origin and course of affective disorders (pp. 113-129). London: Gaskell Royal College of Psychiatrists.

Inoff-Germain, G., Nottelmann, E.D. \& Radke-Yarrow, M. (1997). Relation of parental affective illness to family, dyadic, and individual functioning: An observational study of family interaction. American Journal of Orthopsychiatry, 67(3), 433-448.

Jacobsen, T., Miller, L.J., \& Kirkwood, K.P. (1997). Assessing parenting competency in individuals with severe mental illness: A comprehensive service. Journal of Mental Health Administration, 24(2), 189-199.

Johnston, D. (1991). Jailed mothers. Pasadena, CA: Pacific Oaks Center for Children of Incarcerated Parents. 
Johnston, D. (1992). Children of offenders. Pasadena, CA: Pacific Oaks Center for Children of Incarcerated Parents.

Johnston, D. (1995). Effects of parental incarceration. In K. Gabel \& D. Johnson (Eds.), Children of incarcerated parents (pp. 59-88). New York: Lexington Books.

Joseph, J.G., Joshi, S., Lewin, A.B. \& Abrams, M. (1999). Characteristics and perceived needs of mothers with serious mental illness. Psychiatric Services, 50(10), 1357-1359.

Kalichman, S.C., Adair, V., Somlai, A.M. \& Weir, S.S. (1995). The perceived social context of AIDS: Study of inner-city sexually transmitted disease clinic patients. AIDS Education \& Prevention, 7(4), 298-307.

Katz-Leavy, J., Nicholson, J., Banks, S., Hinden, B. and Lambert, L. (2001, February). Familycentered systems of care: The challenge of parental mental illness. Presented at the $14^{\text {th }}$ Annual Research Conference for Children's Mental Health, Tampa, Florida.

Keitner, G.I. \& Miller, I.W. (1990). Family functioning and major depression: An overview. American Journal of Psychiatry, 147(9), 1128-1137.

Kelly, R.H., Danielsen, B.H., Golding, J.M., Anders, T.F., Gilbert, W.M. \& Zatzick, D.F. (1999). Adequacy of prenatal care among women with psychiatric diagnoses giving birth in 1994 and 1995. Psychiatric Services, 50(12), 1584-1590.

Kendler, K.S., \& Diehl, S.R. (1993). The genetics of schizophrenia: A current, geneticepidemiologic perspective. Schizophrenia Bulletin, 19(2), 261-285.

Kendler, K.S. \& Gardner, C.O. (1997). The risk for psychiatric disorder in relatives of schizophrenic and control probands: A comparison of three independent studies. Psychological Medicine, 27(2), 411-419.

Kerr, S. (2000). The application of the Americans with disabilities act to the termination of the parental rights of individuals with mental disabilities. Journal of Contemporary Law \& Policy, 16, 387.

Kessler, R.C. (1994). The National Comorbidity Survey of the United States. International Review of Psychiatry, 6(4), 365-376.

Kessler, R.C., Anthony, J.C., Blazer, D.G., Bromet, E., Eaton, W.W., Kendler, K., Schwartz, M., Wittchen, H.-U. \& Zhao, S. (1997). The US National Comorbidity Survey: Overview and future directions. Epidemiologia e Psichiatria Sociale, 6, 4-16.

Kliegman, R., Maduna, D. Diwi, R. \& Eisenberg, I. (1994). Relation of maternal cocaine use to the risks of prematurity and low birth weight. Journal of Pediatrics, 124, 751-756.

Knitzer, J. (2000). Promoting resilience: Helping young children and parents affected by substance abuse, domestic violence and depression in the context of welfare reform. 
Children and Welfare Reform Issue Brief 8. New York: National Center for Children in Poverty.

Kochanska, G., Kuczynski, L., Radke-Yarrow, M. \& Welsh, J.D. (1987). Resolutions of control episodes between well and affectively ill mothers and their young children. Journal of Abnormal Child Psychology, 15, 441-456.

Lennon, M.C., Blome, J. \& English, K. (2001). Depression and low income women: Challenges for TANF and welfare-to-work policies and programs. Substance Abuse and Mental Health Services Administration, Center for Mental Health Services. Rockville, MD

Levin, B.L., \& Blanch, A.K. (1998). Women's mental health services: A public health perspective. Thousand Oaks: Sage Publications, Inc.

Mallen, L. (1999, June 14). Model program: Program helps keep families together when a parent has mental illness. Mental Health News Alert Grant Opportunities. CD Publications.

Marsh, D.T. (1996). Meeting the needs of offspring. The Journal of the California A.M.I., 7(3), 56-57.

Marsh, D.T., Appleby, N.F., Dickens, R.M., Owens, M. \& Young, N.O. (1993). Anguished voices: Impact of mental illness on siblings and children. Innovations \& Research, 2(2), 25-33.

Mason, D.A. \& Frick, P.J. (1994). The heritability or antisocial behavior: A meta-analysis of twin and adoption studies. Journal of Psychopathology and Behavioral Assessment, $\underline{16}(4), 301-323$.

McGrew, J.H., Wilson, R.G. \& Bond, G.R. (1996). Client perspectives on helpful ingredients of assertive community treatment. Psychiatric Rehabilitation Journal, 19(3), 13-21.

Melnick, S. (1999). Parenting Issues for Women with Co-Occurring Mental Health and Substance Abuse Disorders who have Histories of Trauma. Fact sheet. Women with CoOccurring Disorders and Violence Coordinating Center. Policy Research Associates, Delmar, NY.

Miller, L.J. (1990). Psychotic denial of pregnancy: Phenomenology and clinical management. Hospital and Community Psychiatry, 41(11), 1233-1237.

Miller, L.J. (1994). Use of electroconvulsive therapy during pregnancy. Hospital and Community Psychiatry, 45, 444-450.

Miller, L.J. (1997). Sexuality, reproduction, and family planning in women with schizophrenia. Schizophrenia Bulletin, 23 (4 1997), 623-635.

Miller, L.J. \& Finnerty, M. (1996). Sexuality, pregnancy, and childrearing among women with schizophrenia-spectrum disorders. Psychiatric Services, 47(5), 502-506. 
Miller, W., Resnick, M.P., Williams, M.H. \& Bloom, J.D. (1990). The pregnant psychiatric inpatient: A missed opportunity. General Hospital Psychiatry, 12(6), 373-378.

Moore, K.A., Zaslow, M.J., Coiro, M.J., Miller, S. \& Magenheim, E. (1996). The JOBS evaluation: How well are they faring? Washington, DC: U.S. Department of Health and Human Services.

Mosier, T.L. (1998). Trying to cure a seven-year itch: The ADA defense in termination of parental rights actions. Brandeis Law Journal, 37, 785.

Mowbray, C.T., Oyserman, D. \& Ross, S.R. (1995a). Parenting and the significance of children for women with a serious mental illness. Journal of Mental Health Administration, $\underline{22}(2), 189-200$.

Mowbray, C.T., Oyserman, D., Saunders, D. \& Rueda-Riedle, A. (1998). Women with severe mental disorders: Issues and service needs. In B. L. Levin \& A. K. Blanch (Eds.), Women's mental health services: A public health perspective (pp. 175-200). Thousand Oaks, CA: Sage Publications.

Mowbray, C.T., Oyserman, D., Zemencuk, J.K. \& Ross, S.R. (1995b). Motherhood for women with serious mental illness: Pregnancy, childbirth, and the postpartum period. American Journal of Orthopsychiatric, 65(1), 21-38.

Mowbray, C.T., Schwartz, S., Bybee, D., Spang, J., Rueda-Riedle, A. \& Oyserman, D. (2000). Mothers with a mental illness: Stressors and resources for parenting and living. Families in Society, 81(2), 118-129.

Mueser, K.T., Bond, G.R., Drake, R.E., \& Resnick, S.G. (1998). Models of community care for severe mental illness: A review of research on case management. Schizophrenia Bulletin, $\underline{24}(1), 37-74$.

Mueser, K.T., Drake, R.E. \& Bond, G.R. (1997). Recent advances in psychiatric rehabilitation for patients with severe mental illness. Harvard Review of Psychiatry, 5(3), 123-137.

Mullick, M., Miller, L.J. \& Jacobsen, T. (2000). Insight into mental illness and child maltreatment risk in mothers with major psychiatric disorders. Unpublished manuscript.

Musick, J.S., Stott, F.M., Spencer, K.K., Goldman, J. \& Cohler, B. (1987). Maternal factors related to vulnerability and resiliency in young children at risk. In B. J. Cohler (Ed.), The Invulnerable Child (pp. 229-253). New York: The Guilford Press.

National Center on Addiction and Substance Abuse (1999, January). No Safe Haven: Children of Substance-Abusing Parents. Columbia University: New York, New York.

Nicholson, J. (1994). [Massachusetts regional clinician data]. Unpublished raw data.

Nicholson, J. (1998, October). Mothers with mental illness and childhood trauma. Paper presented at the meeting of the Institute of Psychiatric Services, Los Angeles, CA. 
Nicholson, J. (1996). Services for parents with mental illness and their families. The Journal of the California AMI, 7(3), 66-68.

Nicholson, J., Biebel, K., Hinden, B., Henry, A. \& Stier, L. (2000). [1999 SMHA survey: SMHA responses to parents with mental illness]. Unpublished raw data.

Nicholson, J. \& Blanch, A. (1994). Rehabilitation for parenting roles for people with serious mental illness. Psychosocial Rehabilitation Journal, 18(July), 109-119.

Nicholson, J., Geller, J.L. \& Fisher, W.H. (1996). "Sylvia Frumkin" has a baby: A case study for policymakers. Psychiatric Services, 47(5), 497-501.

Nicholson, J., Geller, J.L., Fisher, W.H. \& Dion, G.L. (1993). State policies and programs that address the needs of mentally ill mothers in the public sector. Hospital and Community Psychiatry, 44 (May), 484-489.

Nicholson, J. \& Henry, A.D. (in press). Programs for mothers with mental illness: The value of a rehabilitation approach. In L. J. Miller \& K. Kim (Eds.), Major mental illness in women. Gordon and Breach Science Publishers.

Nicholson, J., Larkin, C., Simon, L., \& Banks, S. (2001). The prevalence of parenting among adults with mental illness. Working paper, Center for Mental Health Services Research, Department of Psychiatry, University of Massachusetts Medical School.

Nicholson, J., Nason, M., Calabresi, A. \& Yando, R. (1999). Fathers with Severe Mental Illness: Characteristics and Comparisons. American Journal of Orthopsychiatric, 69(1), 134141.

Nicholson, J., Sweeney, E.M., \& Geller, J.L. (1998a). Mothers with mental illness: I. The competing demands of parenting and living with mental illness. Psychiatric Services, $\underline{49}(5), 635-642$.

Nicholson, J., Sweeney, E.M., \& Geller, J.L. (1998b). Mothers with mental illness: II. Family relationships and the context of parenting. Psychiatric Services, 49(5), 643-649.

Nolan-Hoeksema, S., Girgus, J.S. \& Seligman, M.E. (1992). Predictors and consequences of childhood depressive symptoms: A five-year longitudinal study. Journal of Abnormal Psychology, 101, 405-422.

Norman, J.A. (1995). Children of prisoners in foster care. In K. Gabel \& D. Johnson (Ed.), Children of Incarcerated Parents (pp. 124-134). New York: Lexington Books.

Osofsky, J.D. (1995). The effects of violence exposure on young children. American Psychologist, 50, 782-788.

Overstreet, S. \& Braun, S. (2000). Exposure to community violence and post-traumatic stress symptoms: Mediating factors. American Journal of Orthopsychiatry, 70, 263-271. 
Oyserman, D., Mowbray, C.T., Meares, P.A. \& Firminger, K.B. (2000). Parenting among mothers with a serious mental illness. American Journal of Orthopsychiatric, 70(3), 296315.

Oyserman, D., Mowbray, C.T. \& Zemencuk, J.K. (1994). Resources and supports for mothers with severe mental illness. Health and Social Work, 19(5), 133-142.

Phillips, S. \& Harm, N.J. (2001). Responding to the needs of children of incarcerated mothers. National Association of Family Based Services. Retrieved July 27, 2001 from the World Wide Web: http://www.nafbs.org/96proc/prison.html.

Puckering, C. (1989). Annotation: Maternal depression. Journal of Child Psychology and Psychiatry \& Allied Disciplines, 30(6), 807-817.

Radke-Yarrow, M., McCann, K., DeMulder, E., Belmont, B., Martinez, P. \& Richardson, D.T. (1995). Attachment in the context of high-risk conditions. Development \& Psychopathology, 7(2), 247-265.

Radke-Yarrow, M. \& Sherman T. (1990). Hard growing: Children who survive. In J. Rolf \& A.S. Masten (Eds.), Risk and protective factors in the development of psychopathology (pp. 97-119). Cambridge, England: Cambridge University Press.

Rauber, D.B. \& Granik, L.A. (2000). Representing parents in child welfare cases: A basic introduction for attorneys. (2nd ed.). Washington D.C.: National Bar Association.

Reed, B.G. \& Mowbray, C.T. (1999). Mental illness and substance abuse: Implications for women's health and health care access. JAMWA, 54, 71-78.

Ritsher, J.E., Coursey, R.D. \& Farrell, E.W. (1997). A survey on issues in the lives of women with severe mental illness. Psychiatric Services, 48(10), 1273-1282.

Rogosch, F.A., Mowbray, C.T. \& Bogat, G.A. (1992). Determinants of parenting attitudes in mothers with severe psychopathology. Development \& Psychopathology, 4(3), 469-487.

Rudolph, B., Larson, G.L., Sweeny, S., Hough, E.E. \& Arorian, K. (1990). Hospitalized pregnant psychotic women: Characteristics and treatment issues. Hospital \& Community Psychiatry, 41(2), 159-163.

Sameroff, A.J., Barocas, R. \& Seifer, R. (1978). The early development of children born to mentally ill women. In N. F. Watts (Ed.), Children at risk for schizophrenia (pp. 482514). Cambridge: Cambridge University Press.

Sameroff, A.J. \& Seifer, R. (1983). Familial risk and child competence. Child Development, 54, 1254-1268.

Sands, R.G. (1995). The parenting experience of low-income single women with serious mental disorders. Families in Society, 76(2), 86-96. 
Sanford, L. (2000, November 17). Working to increase representation for the mentally ill in family law matters. New Hampshire Bar News, 11.

Schwab-Stone, M.E., Ayers, T.S., Kasprow, W., Voyce, C., Barone, C., Shriver, T. \& Weissberg, R.P. (1995). No safe haven: A study of violence exposure in an urban community. Journal of the American Academy of Child \& Adolescent Psychiatry, 34, $1343-1352$.

Shonkoff, J. P. \& Hauser-Cram, P. (1987). Early intervention for disabled infants and their families: A qualitative analysis. Pediatrics, 80(5), 650-656.

Shonkoff, J.P., Hauser-Cram, P., Wyngaarden Krauss, M. \& Upshur, C.C. (1988). Early intervention efficacy research: What have we learned and where do we go from here? Topics in Early Childhood Special Education, 8(1), 81-93.

Shonkoff, J.P. \& Meisels, S.J. (1991). Defining eligibility for services under PL 99-457. Journal of Early Intervention, 15(1), 21-25.

Silverman, M.M. (1989). Children of psychiatrically ill parents: A prevention perspective. Hospital and Community Psychiatry, 40(12), 1257-1265.

Smith, R., Cubis, J., Brinsmead, M., Lewin, T., Singh, B., Owens, P., Eng-Cheng, C., Hall, C., Adler, R., Lovelock, M., Hurt, D., Rowley, M. \& Nolan, M. (1990). Mood changes, obstetric experience and alterations in plasma cortisol, beta-endorphin and corticotrophin releasing hormone during pregnancy and the puerperium. Journal of Psychosomatic Research, 34, 53-69.

Sonderegger, T.B. (1992). Perinatal substance abuse: Research finding and clinical implications. Baltimore, MD: Johns Hopkins University Press.

Stanton, A. (1980). When mothers go to jail. Lexington, MA: Lexington Books.

Stefan, S. (1998). Impact of the law on women with diagnoses of borderline personality disorder related to childhood sexual abuse. In B. L. Levin \& A. K. Blanch (Eds.), Women's mental health services: A public health perspective (pp. 240-278). Thousands Oaks: Sage Publications, Inc.

Stefan, S. (2000). Unequal rights: Discrimination against people with mental disabilities and the American Disabilities Act. American Psychological Association.

Taking a different path: Unwilling to play by HMO rules therapists strike out on their own. (2000, July 10). The Nashua Telegraph.

Tannenbaum, L. \& Forehand, R. (1994). Maternal depressive mood: The role of the father in preventing adolescent problem behaviors. Behaviour Reserach and Therapy, 32(3), 321325. 
Taylor, C.G., Norman, D.K., Murphy Michael J., Jellinek, M., Quinn, D., Poitrast, F.G. \& Goshko, M. (1991). Diagnosed intellectual and emotional impairment among parents who seriously mistreat their children: Prevalence, type, and outcome in a court sample. Child Abuse \& Neglect, 15(4), 389-401.

Taylor, L. \& Ingram, R.E. (1999). Cognitive reactivity and depressotypic information processing in children of depressed mothers. Journal of Abnormal Psychology, 108(2), 202-210.

Telpin, L.A., Abram, K.M. \& McClelland, G.M. (1996). Prevalence of psychiatric disorders among incarcerated women: I. Pretrail jail detainees. Archives of General Psychiatry, 53(6), 505-512.

Tienari, P., Wynne, L.C., Moring, J. \& Lathi, I.(1994). The Finnish adoptive family study of schizophrenia: Implications for family research. British Journal of Psychiatry, 164(23), 20-26.

Todd, R.D., Reich, W., Petti, T.A., Joshi, P., DePaulo, R., Nurnberger, J. \& Reich, T. (1996). Psychiatric diagnoses in the child and adolescent members of extended families identified through adult bipolar affective disorder probands. Journal of the American Academy of Child \& Adolescent Psychiatry, 35(5), 664-671.

U.S. Department of Health and Human Services. (2000a). Mental Health: A Report of the Surgeon General. Substance Abuse and Mental Health Services Administration, Center for Mental Health Services, National Institutes of Health, National Institute of Mental Health. Rockville, MD.

U.S. Department of Health and Human Services (2000b). State Profiles, 1999, on Public Sector Managed Behavioral Health Care. Substance Abuse and Mental Health Services Administration, Office of Managed Care. Rockville, MD.

Walker, E. \& Emory, E. (1983). Infants at risk for psychopathology: Offspring of schizophrenic parents. Child Development, 54, 1269-1285.

Warner, V., Mufson, L. \& Weissman, M. (1995). Offspring at high and low risk for depression and anxiety: Mechanisms of psychiatric disorder. Journal of the American Academy of Child \& Adolescent Psychiatry, 34(6), 786-797.

Webster, J. (1992). Split in two: Experiences of the children of schizophrenic mothers. British Journal of Social Workers, 22(3), 309-329.

Weinhardt, L.S., Carey, M.P. \& Carey, K.B. (1998). HIV-risk behavior and the public health context of HIV/AIDS among women living with a severe and persistent mental illness. Journal of Nervous \& Mental Disease, 186(5), 276-282.

Weintraub, S. (1987). Risk factors in schizophrenia: The Stony Brook high-risk project. Schizophrenia, 13(3), 439-449. 
Weintraub, S. \& Neal, J. M. (1984). Social behavior of children at risk for schizophrenia. In N. Watt. E. J. Anthony, L. C. Wynne and J. E. Rolf (Eds.), Children at risk for schizophrenia: A longitudinal perspective (pp. 243-263). New York: Cambridge University Press.

Weissman, M.M. (1989). Anxiety disorders in parents and children: A genetic-epidemiological perspective. In J. S. Reznick (Ed.), Perspectives on behavioral inhibition (pp. 241-254). Chicago: University of Chicago Press.

White, C.L., Nicholson, J., Fisher, W.H. \& Geller, J.L. (1995). Mothers with severe mental illness caring for children. The Journal of Nervous and Mental Disease, 183(6), 398403.

Wickramaratne, P.J. \& Weissman, M.M. (1998). Onset of psychopathology in offspring by developmental phase and parental depression. American Journal of Child and Adolescent Psychiatry, 37, 933-942.

Williams, A.B. (1990). Reproductive concerns for women at risk for HIV infection. Journal of Nurse Midwifery, 35(5), 292-298.

Wright, L. \& Seymour, C.B. (2000). Working with Children and Families Separated by Incarceration. Child Welfare League of America.

Zeitz, M.A. (1995). The mothers' project: A clinical case management system. Psychiatric Rehabilitation Journal, 19(1), 55-62.

Zemencuk, J., Rogosch, F.A. \& Mowbray, C.T. (1995). The seriously mentally ill women in the role of parent: Characteristics, parenting, sensitivity, and needs. Psychosocial Rehabilitation Journal, 18(1), 77-92.

Zigler, E. (1998). By what goals should Head Start be assessed. Children's Services: Social Policy Research, and Practice, 1(1), 5-17. 


\section{Appendix}

National Advisory Group on Parents with Psychiatric Disorders and their Families

October 18-19, 1999 $\approx$ Bethesda, Maryland

Sponsored by the Center for Mental Health Services,

of the Substance Abuse and Mental Health Services Administration

\section{List of Participants}

Jeanette Bevett-Mills

CSAP Prevention/SAMHSA

Rockville, MD

Kathleen Biebel, M.S.

University of Massachusetts Medical School

Worcester, MA

Nancy Davis, Ed.D.

CMHS/SAMHSA

Rockville, MD

Kana Enomoto, M.A.

CMHS/DKDSC

Rockville, MD

Roger Fallot, Ph.D.

Community Connections

Washington, DC

Melinda Fox, M.A.

New Hampshire-Dartmouth Psychiatric Research Center

Concord, $\mathrm{NH}$

Barbara Friesen, Ph.D.

Portland State University

Portland, OR

Alexis Henry, Sc.D.

University of Massachusetts Medical School

Worcester, MA

Betsy Hinden, Ph.D.

University of Massachusetts Medical School

Worcester, MA 
Gail P. Hutchings, M.P.A.

National Association of State Mental Health Program Directors

Alexandria, VA

Judith Katz-Leavy, M.Ed.

CMHS/SAMHSA

Rockville, MD

Lucinda Sloan Mallen

Mental Health Association in Orange County, Inc.

Goshen, NY

Melissa Mireles

CMHS/SAMHSA

Rockville, MD

Carol Mowbray, Ph.D.

University of Michigan-School of Social Work

Ann Arbor, MI

Joanne Nicholson, Ph.D.

University of Massachusetts Medical School

Worcester, MA

Peg O'Neil

National Mental Health Association

Alexandria, VA

Roseann Rafferty, M.S.W.

NIDRR/Department of Education

Washington, DC

Susan Salasin

CMHS/SAMHSA

Rockville, MD

Ulonda Shamwell, M.S.W.

CMHS/SAMHSA

Rockville, MD

Melanie Shaw, Esq.

Disability Advocates

Albany, NY 


\author{
Larry Stier \\ University of Massachusetts Medical School \\ Worcester, MA \\ Gina Tesauro, M.S.W. \\ National Cancer Institute \\ Bethesda, MD \\ Marty Zaslow, Ph.D. \\ ChildTrends \\ Washington, DC
}

